OPEN ACCESS

Edited by:

Wulf Rössler,

Charité - Universitätsmedizin

Berlin, Germany

Reviewed by:

Conrad Stanisław Zygmont, Helderberg College, South Africa Thomas Doherty,

Thomas Doherty, United States

*Correspondence:

Myriam V. Thoma

m.thoma@psychologie.uzh.ch

Specialty section:

This article was submitted to Public Mental Health a section of the journal

Frontiers in Psychiatry

Received: 12 March 2021 Accepted: 26 April 2021 Published: 21 May 2021

Citation:

Thoma MV, Rohleder N and

Rohner SL (2021) Clinical Ecopsychology: The Mental Health Impacts and Underlying Pathways of the Climate and Environmental Crisis.

Front. Psychiatry 12:675936.

doi: 10.3389/fpsyt.2021.675936

\section{Clinical Ecopsychology: The Mental Health Impacts and Underlying Pathways of the Climate and Environmental Crisis}

\author{
Myriam V. Thoma ${ }^{1,2 *}$, Nicolas Rohleder ${ }^{3}$ and Shauna L. Rohner ${ }^{1,2}$ \\ ${ }^{1}$ Psychopathology and Clinical Intervention, Institute of Psychology, University of Zürich, Zurich, Switzerland, ${ }^{2}$ University \\ Research Priority Program "Dynamics of Healthy Aging," University of Zürich, Zurich, Switzerland, ${ }^{3}$ Friedrich-Alexander \\ University Erlangen-Nürnberg, Chair of Health Psychology, Erlangen, Germany
}

Humankind is confronted with progressing climate change, pollution, environmental degradation, and/or destruction of the air, soil, water, and ecosystems. The climate and environmental crisis is probably one of the greatest challenges in the history of humankind. It not only poses a serious current and continuing threat to physical health, but is also an existing and growing hazard to the mental health of millions of people worldwide. This synergy of literature provides a current summary of the adverse mental health impacts of the climate and environmental crisis from the perspective of Clinical Psychology. Furthermore, it presents potential underlying processes, including biological, emotional, cognitive, behavioral, and social pathways. The existing data suggest that the climate and environmental crisis not only acts as a direct stressor, but can also exert a detrimental impact on the various pathways, with the potential to amplify an individual's biopsychosocial vulnerability to develop mental ill-health. This is a call for an increased investigation into this emerging research field of Clinical Ecopsychology by clinical psychologists and other researchers.

Keywords: mental health, mental disorder (disease), climate change, vulnerability, resilience

\section{INTRODUCTION}

The human impact on the Earth has become so meaningful that the present geological epoch has been termed the "Anthropocene", i.e., a time of significant human-created geological change (1). This definition of the Anthropocene gives equal consideration to the potentially positive, as well as negative, imprints of humankind on Earth. On a positive note, the progressively globalized social system, a core attribute of the Anthropocene (2), has led to the unprecedented opportunity to share and grow knowledge across the globe, to promote social connections, and to allow an unparalleled global mobility. On a negative note, the rapidly growing human population has had a largescale impact on the Earth in the form of an unprecedented pollution, environmental degradation, destruction of the air, soil, water, and ecosystems, as well as the mass destruction of species across the globe. The human imprint has triggered climate and environmental changes that have the potential to endanger the survival of the human race. In fact, the growing existential threat posed by this anthropogenic climate change has led 11,258 scientists from over 150 countries to come together to warn people about the climate emergency (3). The anthropogenic climate change is not 


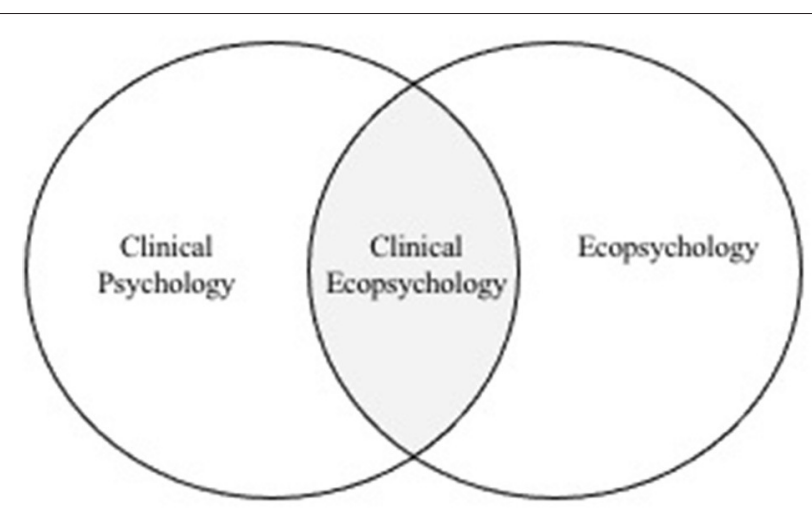

FIGURE 1 | Placement of the research field "Clinical Ecopsychology" between "Clinical Psychology" and "Ecopsychology".

only regarded as “... potentially the biggest global health threat in the twenty-first century" [(4), p. 1,693], but is arguably one of the most important challenges in the history of humankind.

This human-driven climate and environmental crisis can both directly and indirectly influence health and well-being. While the focus of prior research was directed toward physical health, comparatively little research exists on the mental health impacts. However, the investigation of the mental (ill-)health implications of the progressing climate change, pollution, environmental degradation, and/or destruction of the air, soil, water, and ecosystems is a rapidly expanding research field (5-9). The growing interest in this area can be demonstrated by the number of publications on the topic "climate change and mental health" in PubMed, which sharply increased in 2020 with 120 new publications, compared to just 69 in 2019. This research area warrants particular consideration, given the evolving urgency of the climate and environmental crisis, combined with the growing body of evidence of a substantial impact by the ongoing crisis on mental health, and paired with the exponentially growing number of publications on the topic. Special attention can be focused on evolving phenomena such as this by the provision of a distinct and precisely defined area within which to capture such research. As such, we herewith propose "Clinical Ecopsychology" as an umbrella term for existing and future research efforts that are dedicated to fostering the understanding of the development of mental ill-health in response to the climate and environmental crisis. Given that Clinical Ecopsychology may be best described as being an overlapping field of "Clinical Psychology" and "Ecopsychology" (see Figure 1), both research fields will be described in more detail in the following sections. As this work is written from the perspective of Clinical Psychology, a stronger focus is placed on this particular field.

\section{Clinical Psychology}

Clinical Psychology is a discipline that is involved in the research, assessment, diagnosis, and treatment of mental illhealth [e.g., (10)]. At the core of Clinical Psychology lies the motivation to understand the complex nature of the etiology of mental ill-health, as well as the determination to optimally diagnose psychopathology. The overarching aim is to develop new, further improve existing, and supply efficient and evidence-based treatment options. The Diagnostic and Statistical Manual of Mental Disorders, in its fifth edition [DSM5, (11)], as well as the 10th (and soon 11th) Revision of the International Statistical Classification of Diseases and Related Health Problems [ICD-10, (12)], assist clinical psychologists and others in the diagnosis of mental health disorders for research and practice. Clinical Psychology can thus offer the expertise and knowhow to investigate, assess, describe, and diagnose potentially psychopathological responses to the current climate and environmental crisis. To better understand the impact of the climate and environmental crisis on mental health, we can therefore draw from models in Clinical Psychology.

A central model in Clinical Psychology is the vulnerabilitystress model $(13,14)$, according to which mental health disorders develop as a result of an interaction between the presence of stress and an individual's vulnerability (or sensitivity) to stress. This vulnerability results from the interplay of biological, psychological, and social dimensions. The biological dimension encompasses aspects related to physical health and physiological functioning, including genetic, hormonal, and immunological makeup; but also (mal)nutrition, (non-)communicable diseases, and injuries. The psychological dimension includes emotional, cognitive, and behavioral aspects, such as dysfunctional emotion regulation strategies or negative cognitive schemata. The social dimension includes aspects such as interpersonal conflicts or loneliness. Depending on the interplay of these factors, vulnerability is formed that renders an individual more or less susceptible to stress and the subsequent development of mental ill-health $(13,14)$.

Existing findings on the mental health implications of various climate and environmental stressors support the notion that these stressors can exert a meaningful impact on mental health via biological, psychological, and social pathways. Furthermore, these pathways do not act in isolation, but rather interact with each other, as can be shown in a study with Inuit in Canada (15): It was found that climate change-related alterations to the natural environment (e.g., ice instability) profoundly interfered with their traditional, land-based lifestyle, i.e., how they work, travel, and gather food (behavioral pathway). This in turn negatively affected diet and activity patterns (biological pathway), cultural identity, connection to the land, sense of place, and self-worth (cognitive pathway). This was further linked to despair, sadness, or hopelessness (emotional pathway); and can also impact social behavior (social pathway) [see also (16)]. The Inuit situation is a very good living example, which impressively shows the diversity of the impact of a changing natural environment, and the interwovenness of the underlying pathways. Through the application of the vulnerability-stress model $(13,14)$, this example demonstrates how Clinical Psychology can offer a useful explanatory model that can be applied in the understanding of the development of mental ill-health in response to the current climate and environmental crisis.

Current directions in Clinical Psychology include, but are not limited to, the combination of clinical psychological research with collected knowledge from clinical experience and practice, 
the development of evidence-based treatment guidelines, crosscultural considerations in the diagnosis of psychopathology and culturally responsive care, the facilitation of low-threshold accesses for the treatment of mental health problems (e.g., using e-mental health interventions), the increased attention to (the treatment of) mental (ill-)health in adults of advanced age, and the adopting of a multisystem perspective on resilience [e.g., (1719)]. These current directions in Clinical Psychology align with the demands posed by the climate and environmental crisis. It is therefore important not to miss the opportunity to apply the expertise of the large and influential field of Clinical Psychology to the current and constantly evolving climate and environmental crisis. In fact, the field of Clinical Psychology is becoming increasingly aware of the mental health impacts of the crisis [e.g., (20)]. For example, this increasing awareness was reflected in the organization of the first International Summit on Psychology and Global Health in 2019, held in Portugal, which was attended by leaders of multiple psychological associations from over 40 nations (21). At this gathering, the leaders declared an agreement to employ psychological research to fight climate change.

However, despite the readiness of Clinical Psychology to address the climate and environmental crisis, certain barriers exist that may also hinder an in-depth dedication to this emerging research field. Such barriers include, but are not limited to: (a) the vast complexity of the anthropogenic climate and environmental crisis, and the resulting difficulty to attribute a causal link between the climate and environmental crisis and mental illhealth (22); (b) the multiple possible direct and indirect impacts on various biopsychosocial life-domains, which are challenging to assess; (c) the general complexity of the etiology of mental health disorders; (d) the potential personal reluctance to deal with this topic due to a lack of knowledge (e.g., regarding the human-nature relationship), personal fears, or potential denial of the climate and environmental crisis; and finally, (e) clinical psychologists working in research or clinical practice may have to focus on more immediate or urgent priorities. For instance, while the Covid-19 crisis has shed light on the importance of mental health [e.g., (23)], it has also undeniably upstaged the ongoing climate and environmental crisis. Targeting such barriers can help facilitate the effective integration of Clinical Psychology in addressing the climate and environmental crisis.

\section{Ecopsychology}

Ecopsychology has "... a healthy diversity in conceptions" [see for instance, (24), p. 2], which can make it difficult to provide an allencompassing, commonly-accepted definition of Ecopsychology. Broadly, Ecopsychology can be described as the research field dedicated to the study of the connection between human-caused changes to and destruction of the natural world ".... and the spiritual or psychological crises resulting from our increasing experience of separation from the more-than-human world. Ecopsychology looks for the roots of environmental problems in human psychology and society and for the roots of some personal and social problems in our dysfunctional relationship to the natural world." [(25), p. 68]. "Ecopsychology explores humans' psychological interdependence with the rest of nature and the implications for identity, health and well-being. Ecopsychology topics include emotional responses to nature; the impacts of environmental issues such as natural disasters and global climate change; and the transpersonal dimensions of environmental identity and concern" [(26), Ecopsychology section, para. 1].

Ecopsychology is one of six core sub-fields of Environmental Psychology, in addition to "Behavior and the Built Environment," "Conservation Psychology," "Psychology on the Population Level," "Teaching Psychology for Sustainability," and "Using Film to Demonstrate Environment and Behavior" [(27), Interest Areas section]. According to Scull (25), in addition to its connection to Environmental Psychology, the field of Ecopsychology is related to several other larger fields, such as Psychotherapy, Spirituality, and Philosophy. Ecopsychology itself is comprised of multiple sub-disciplines, which include (but are not restricted to) sub-categories, such as Nature, Spirituality, Transpersonal Psychology, Environmental Activism, Experiential Environmental Education, Human Ecology, and Ecotherapy and Nature Connection (25). As such, Ecopsychology can be understood as a multi-faceted field comprised of numerous sub-disciplines that are all dedicated to the various aspects of the human-nature interrelationship.

The therapeutic focus of Ecopsychology has been explicitly stated (24), and is a core component of this field [e.g., (28)]. This relates to the assumption of Ecopsychology that human beings are closely attached to nature. This close emotional and spiritual bond and connection to nature is proposed to be due to the phylogenetic development of the modern human, which lasted hundreds of thousands of years and involved surviving in close interconnection with the natural world [e.g., (29, 30)]. Given this evolutionary "up-bringing" in nature, living in equilibrium with nature is thought to be a crucial prerequisite for humans' physical and mental health and well-being (31). While Ecopsychology and Clinical Psychology both have their place in understanding the mental health impacts of the climate and environmental crisis, a distinct research area drawing on the most relevant elements of each field can help advance this research topic further.

\section{Clinical Ecopsychology}

Clinical Ecopsychology seeks to systematically examine the direct and indirect mental health impacts of the progressing climate change, pollution, environmental degradation, and/or destruction of the air, soil, water, and ecosystems. More specifically, Clinical Ecopsychology sets out to examine underlying pathways of how the climate and environmental crisis can lead to the development of mental ill-health, which entails the study of specific risk and vulnerability factors. Clinical Ecopsychology also investigates potential protective and resilience factors that may aid individuals in their adaptation and that may foster the maintenance of mental health in the face of the ongoing crisis. Clinical Ecopsychology further aims to thoroughly examine the beneficial mental-health impact of contact with the natural world. Taken together, Clinical Ecopsychology sets out to examine underlying pathways that lead to the development of mental ill-health in the face of ecological adversity. This involves the study of risk, vulnerability, and protective factors to understand interindividual differences in the response and adaptation to 
ecological adversity, and the promotion of (the creation of) efficient treatment options for mental health disorders linked to the climate and environmental crisis.

It must be noted that Clinical Ecopsychology is not a new research field. Both Clinical Psychology, but in particular Ecopsychology (in addition to Environmental and Conservation Psychology), have previously made extremely valuable contributions to the understanding of these topics [see for instance (32-37)]. As such, Clinical Ecopsychology may also be described as a respective sub-category of these fields: Clinical Ecopsychology is a sub-field of Clinical Psychology in its focus on climate and environmental stressors and its consideration of the beneficial impact of nature/natural stimuli, which is an existing, although still vastly neglected and marginal topic within Clinical Psychology. Clinical Ecopsychology is equally a sub-field of Ecopsychology, as it shares many, though not all, interests of Ecopsychology. For instance, Clinical Ecopsychology may not (or only to a very limited extent) deal with topics such as Nature Spirituality, Transpersonal Psychology, or Environmental Activism, which are sub-disciplines of Ecopsychology (25). Clinical Ecopsychology may also draw on more "clinical" language than Ecopsychology, such as when describing therapeutic processes and outcomes (e.g., to "treat" rather than to "heal"). However, while Clinical Ecopsychology may be most optimally placed between Clinical Psychology and Ecopsychology (i.e., through their shared overlap), this should not mask the fact that Clinical Ecopsychology is in itself a multi-disciplinary research field. In fact, an impressive and rich variety of disciplines (e.g., Psychiatry, Psychology, Medical Sciences, Sociology, Public Health, and Biology) have already contributed to the increasing understanding of the mental health impacts of the climate and environmental crisis. The multiple disciplines from which it is possible to examine the mentalhealth impact of the climate and environmental crisis mirrors the multi-dimensionality of (the development of) mental ill-health.

As stated above, Clinical Ecopsychology not only focuses on the development of mental ill-health in response to the climate and environmental crisis; but also aims to foster a better understanding of how mental health can be upheld in the face of the ongoing crisis, and how mental health disorders linked to ecological adversity can be most optimally treated. Potentially useful therapeutic approaches include the validation and management of emotional responses, verbalization of (complex) emotions, fostering active hope, finding a balance between pessimism and optimism, stimulating self-efficacy, promoting social connectedness, and training adaptive emotion regulation strategies [e.g., (38)]. Cognitive strategies can also be used to foster functional cognitive coping mechanisms, such as cognitive reframing, problem solving, reflection of responsibility and own contribution, putting negative thoughts into perspective, and radical acceptance [e.g., $(39,40)]$. Depending on the needs of the individual, single or group settings should be offered, and low-threshold options should be made available, such as informal meetings with like-minded individuals. These informal meetings may be particularly important, as previous research has shown that becoming active through collective group engagement is linked to hope, a key protective factor in dealing with eco-anxiety:
"Hope can help them confront the problem and bear the burden of taking on climate change without becoming overwhelmed" [(41), p. 13]. Furthermore, given the positive impact of natural stimuli, contact with nature and natural elements should be integrated whenever possible into psychotherapeutic work on the topics of Clinical Ecopsychology [for an overview see (42)]. For instance, research on a form of nature therapy called Shinrinyoku, in which individuals spend time in the forest, has shown reductions in mental fatigue through decreased prefrontal cortex activity, reduced cortisol concentrations, and increased feelings of comfort and calm (43). The deep-rooted psychophysiological connection to nature may help individuals to (sub-)consciously resonate with the natural environment and to respond positively to its restorative influence (44-47).

In conclusion, it is the aim of Clinical Ecopsychology to combine existing multi-disciplinary forces in order to create, share, and promote the necessary knowledge required for: (a) raising awareness of the increasing psychopathology stemming from anxiety, frustration, and despair associated with the climate and environmental crisis; (b) the maintenance of mental health in the face of ecological adversity; (c) the efficient treatment of mental health disorders linked to ecological adversity; (d) increasing access to mental health care across the globe, particularly in those regions most affected by the crisis; (e) the planning and implementation of intervention measures; and (f) the provision of additional research-based arguments for the urgently needed global action on the current and worsening climate and environmental crisis.

\section{Aim and Structure of This Synergy of Literature}

Given the wide-ranging, and diverse multidisciplinary literature on the mental health impact of the climate and environmental crisis, a systematic literature search was not considered feasible nor the goal of this report. Instead, this synergy of literature aims to extend existing research by providing a current overview of the core and most recent lines of research by summarizing the existing literature from the perspective of Clinical Psychology. The online databases PsychINFO, Web of Science, PubMed, and Scopus were used for the literature search. Furthermore, reference lists of appropriate articles were also screened for additional studies. Search terms related to the following domains were applied: mental health (e.g., mental health disorders, psychopathology), climate change (e.g., climate crisis, global warming), and environmental crisis (e.g., destruction of nature, pollution). Only peer-reviewed articles written in English and published by the end of September 2020 were considered for the synergy of literature.

This article is structured as follows: climate and environmental stressors are first described, followed by an in-depth examination of the mental health impacts of the various ecological stressors. Potential underlying processes are then summarized, encompassing biological and social pathways, as well as the previously neglected emotional, cognitive, and behavioral pathways. The way in which the climate and environmental crisis can amplify an individual's biopsychosocial 
vulnerability is then outlined. This is followed by a description of risk and vulnerability factors, including vulnerable populations, and the potential for increased adaptation to ecological stressors. This synergy of literature concludes with a discussion of methodological considerations and future directions.

\section{CLIMATE AND ENVIRONMENTAL STRESSORS}

The climate and environmental stressors outlined in this report refer to human-created ecological changes. "Human activities are estimated to have caused $\sim 1.0^{\circ} \mathrm{C}$ of global warming above pre-industrial levels, with a likely range of $0.8-1.2^{\circ} \mathrm{C}$. Global warming is likely to reach $1.5^{\circ} \mathrm{C}$ between 2030 and 2052 if it continues to increase at the current rate" [(48), p. 4]. The main driving force behind the increasing temperatures is greenhouse gas emissions, which are linked to economic growth, the steadily growing human population, and the excessive consumption of the wealthy lifestyle (3). Despite continuous warnings about the state of climate change since the First World Climate Conference in 1979, there is no evidence of a decrease in greenhouse gas emissions (3). The consequences of this climate change are manifold, including the loss of ecosystems and biodiversity, the increase in ocean heat and acidity, the melting of the glaciers, the rising sea level, as well as an increase in extreme weather events and natural disasters (48).

In addition to climate change, humans are also responsible for pollution of the air, soil, and water, as well as for the destruction of biospheres and ecosystems, deforestation, and resource extraction. Air pollution, largely caused by the burning of fossil fuels (49), is a major concern in urban areas, particularly in megacities and developing countries: “...91\% of the world's population lives in places where air quality levels exceed WHO limits" [(50), Ambient Air Pollution section, para. 2]. Another major form of pollution comes from mismanaged plastic waste, which is detrimental for oceans and marine wildlife. It was estimated that in 2010 alone, 4.8-12.7 million metric tons of plastic waste entered the ocean (51). Pollution can also be caused by oil spills, such as the Deepwater Horizon Oil Spill in the Gulf of Mexico in 2010, with an estimated discharge of around five million barrels of oil and natural gas. This oil spill spoiled sediment, seawater, marine flora and fauna, as well as commercial seafood species, such as shrimp (52). The unprecedented decline in nature in the history of human beings (53) is so substantial that scientists describe the current loss of biodiversity as the Earth's sixth mass extinction (54). Across the globe, scientists increasingly emphasize biodiversity issues, such as the impact of the extinction of insect populations (55), the need for conservation of subterranean ecosystems (56), or the freshwater biodiversity crisis (57). Of particular concern is the trend in deforestation, with a $49.6 \%$ increase per decade in global tree cover loss over the last 20 years (3).

The effect of this climate and environmental crisis can vary depending on whether the phenomena are acute, sub-acute, or chronic, and whether the effect is experienced more directly or indirectly. Acute events refer to fast-onset disasters, such as extreme weather events or an oil spill. Sub-acute events refers to slow-onset or slow-moving disasters, such as droughts or air pollution. Chronic events refer to more subtle occurrences and insidious changes, such as the rise of sea levels or the decreased livability of habitats in certain regions $(5,9)$. Individuals can be directly affected by disasters via personal exposure, such as through injury, physiological harm, traumatization, but also by abrupt community losses (e.g., by wildfire). In many cases, individuals are indirectly affected through the various impacts of the climate and environmental crisis on their biopsychosocial life-domains. This includes indirect psychosocial impacts triggered by changes to one's socio-environment, such as by damages to the infrastructure of one's hometown by a hurricane, or by experiencing economic hardship and potentially forced migration caused by a climate-change related drought. Another indirect impact relates to the experiencing entity, i.e., the subjective, psychological impact of the climate and environmental crisis. Strong emotional reactions such as fear, sadness, hopelessness, or guilt can arise due to witnessing the crisis from a distance, such as through learning or increased virtual exposure, i.e., confrontation with media representations about the climate and environmental crisis $(5,38,58,59)$. All of these described direct and indirect impacts can co-exist, overlap, and be nested within each other.

While accumulated research evidence has demonstrated physical health effects [e.g., (60)], the investigation of the mental health impacts of climate and environmental stressors is a comparatively recently emerging research area, which can be considered within the frame of Clinical Ecopsychology.

\section{IMPACT ON MENTAL HEALTH}

This section provides a current overview of studies investigating the mental health impact of a variety of climate and environmental stressors.

\section{Impact of Extreme Weather Events and Natural Disasters}

Extreme weather events (e.g., floods), and natural disasters (e.g., wildfires) have been previously linked to a broad range of adverse mental health outcomes (22, 61-66). The most commonly reported mental health disorders in the aftermath of extreme weather events and natural disasters are posttraumatic stress disorder (PTSD) and depression, as well as anxiety, suicide, and substance abuse disorders $(22,67,68)$.

Large differences in prevalence rates are found in studies on the impact of extreme weather events and natural disasters on mental health [i.e., PTSD, 0.7-52.6\%, anxiety disorders, -0.4 to $84 \%$, and depression, $0.9-81 \%$, (65)]. This may be due to multiple factors, such as differences in socio-demographics (e.g., age, sex), disasters (e.g., type, severity), magnitude of exposure, or applied methodological differences (e.g., study design, psychometric instruments) (65). In particular, assessment time plays a critical role, as psychopathological burden varies as a function of time (8). Burden appears to be higher in the short-term, reaching the highest levels within the 1st year post-disaster and attenuates 
thereafter, with variations in peak and trajectory depending on severity of symptomatology $(22,69)$. Nevertheless, despite these prevalence differences, PTSD is repeatedly observed to be the most frequently examined mental health disorder following extreme weather events and natural disasters (70). Given the particular characteristics of these events, such as the suddenness, the destructive potential, and likelihood for severe sequelae (e.g., injury, death); it is unsurprising that such ecological stressors can trigger the development of stress-related mental health disorders.

There is a lack of longitudinal studies on PTSD following extreme weather events and natural disasters, with some notable exceptions. For instance, McLaughlin et al. (62) examined the impact of Hurricane Katrina on PTSD over time. From the affected individuals, $17.1 \%$ were estimated to have PTSD at 719 months (baseline) and $29.2 \%$ at $24-27$ months (follow-up) post-disaster. Around $40 \%$ with PTSD at baseline had recovered by the follow-up. More than $40 \%$ with PTSD at follow-up showed a delayed onset, i.e., onset later than 6 months after the hurricane (62). It should be noted that this study did not obtain pre-disaster data on psychological functioning, which prevented statements about the change in mental health in response to the disaster. However, a set of studies $(63,64,66)$ was able to longitudinally compare psychopathological burden from pre- to post-Hurricane Katrina in a high-risk sample of low-income parents. At around 11 months post-disaster, Rhodes et al. (66) found that serious mental illnesses were twice as high postdisaster $(13.8 \%)$ compared to pre-disaster (6.9\%), with almost half the sample $(47.7 \%)$ showing probable PTSD. Follow-ups were conducted with the same sample at 5 years (63), and 12 years after the hurricane (64). Probable PTSD declined from 33 to $16.7 \%$, suggesting a slow recovery over time. Similarly, non-specific psychological distress also showed an elevation from baseline $(24.0 \%)$ to the first follow-up (35.2\%), with a slow decline thereafter (second follow-up: $30.1 \%$; third followup: $28.5 \%$ ), but remaining above baseline values (64). These studies show that more than a decade after an "acute" natural disaster, adverse mental health effects can still be detected in some survivors.

\section{Impact of Increasing Temperatures and Extreme Heat Event}

Increasing temperatures are resulting in a higher frequency of extreme heat events, such as heat waves (48). The occurrence of these extreme heat events is a major public health problem as they have been linked to a vast array of mental health consequences, including aggressive and criminal behavior, wake and sleep disorders (e.g., insomnia, obstructive sleep apnea), depression, and suicide (71-73). For example, Burke et al. (74) observed an increase in suicide rates in the US and Mexico ( 0.7 and 2.1\%, respectively) between 1990 and 2010, in response to a $1^{\circ} \mathrm{C}$ increase in average monthly temperature (74). In addition, a recent study provided large-scale evidence for the climate change-mental ill-health relationship, by combining meteorological data (between 2002 and 2012) with mental health data from almost two million US residents (75). Results showed that worse mental health was related to short-term exposure to extreme weather events, multiyear warming, and exposure to tropical cyclones (75).

Increasing temperatures have also been linked to higher admission rates to emergency departments and psychiatric hospitals in individuals with pre-existing mental health conditions. For example, in the study by Shiloh et al. (73), a significant association was found between the maximum environmental temperature and psychiatric hospital admission rates of patients with an acute psychotic exacerbation of schizophrenia. This suggests that psychotic symptomatology, such as hallucinations or delusions, can vary as a function of (higher persistent) temperatures, with disturbed sleep as a result of the higher temperatures potentially playing a role (73). These studies show the adverse impact that "chronic" events (i.e., rising temperature) can have on mental health.

\section{Impact of Droughts}

Related to the increasing temperatures, climate change can also increase the likelihood of droughts and precipitation deficits in some world regions (48). Droughts have previously been linked to an increase in general mental distress. For instance, a study examined the mental health impact of a long-lasting drought in Australia and found that in response to the 7-year drought, distress increased in rural (but not urban) habitants by $6.22 \%$ (76). Another Australian study including 8,000 individuals found "...that if the population in rural and regional areas of Australia were not exposed to drought the incidence of mental health problems in these areas would be $10.5 \%$ lower" [(77), p. 187]. An increase in suicide rates during drought periods has repeatedly been reported, but with inconsistent findings across studies [e.g., (71)]. This research demonstrates the adverse effects of "sub-acute" events on mental health.

\section{Impact of Water and Food Insecurity}

Rising temperatures that cause the retreat of glaciers, along with climate-change related variations in precipitation patterns, are leading to a reduction in fresh water resources and in agricultural yield. These changes affect the water and food security of millions of people worldwide, particularly those heavily dependent on rivers and precipitation (78). The impact of climate change on water and food supplies is complex and co-influenced by political, social, and environmental factors (79). Two-thirds of the world population are confronted with severe water scarcity for a minimum of 1 month per year (80); and up to 800 million people are affected by food insecurity (81). These high numbers show that water and food insecurity are large-scale risk factors for health and well-being [e.g., (82)].

Water scarcity has been linked to psychological distress, suicidality, anxiety, hopelessness, and depression [for a review see (83)]. Insecure or scarce access to water can induce worries about material deprivation, shame and stigma for failing social roles or norms (e.g., begging for water, unable to clean oneself), as well as persistent concerns about threats to physical health, such as contaminated water (83). Similarly, food insecurity, and the resulting malnutrition, has not only been linked to physical health conditions (e.g., anemia, adverse physical development), but also mental ill-health (81). A recent systematic review and 
meta-analysis on food insecurity and mental health found an increased risk for depression and stress (84). The association between food insecurity and depression followed a dose-response pattern, with more food insecurity associated with a higher risk for depression, with a higher risk observed for men and older adults (above 65 years) (84). These studies illustrate the negative impact that "sub-acute" events (i.e., water and food insecurity) can have on mental health.

\section{Impact of Air Pollution}

Several studies have examined the impact of air pollution on mental health [for an overview see (85)]. Exposure to (ultra)fine particulate matter has been linked to depressive symptomatology in both cross-sectional (86) and longitudinal (87) research. In the exploratory longitudinal study by Roberts et al. (87), results showed that exposure to concentrations of air pollution at 12 years of age was associated with the development of depressive symptoms and a higher risk of being diagnosed with depression by the age of 18 (87). A recent systematic review and metaanalysis also revealed that ambient particulate matter (with an aerodynamic diameter smaller than $2.5 \mu \mathrm{m}$ ) was strongly associated with an elevated risk of depression and marginally related to a higher risk of suicide (88). Findings further suggest an accumulative detrimental impact over time, with longer exposure to particulate matter associated with greater risk of depression (88). Furthermore, studies on air pollution and suicide have shown increases in the rate of suicides of $1-2 \%$ per day of poor-quality air (71).

In addition, exposure to air pollution has also been linked to cognitive impairment, as well as to diseases affecting the central nervous system (CNS), such as Alzheimer's disease (88-90). For example, a population-based cohort study in Canada found that individuals living in proximity to major roadways with high levels of air and noise pollution had a higher risk of developing dementia (91). Up to $11 \%$ of the dementia incidence within the 11-year observation period could be attributed to the heavy traffic exposure and the related air pollution (91). These studies show the adverse impact that air pollution, a "sub-acute" event, can have on psychological and cognitive health and well-being.

\section{Impact of Profound Changes to the Natural Environment}

Profound changes to the natural environment and landscape, either by human-created destruction (e.g., open mining), destruction through natural forces (e.g., wildfire), or as a consequence of climate change (e.g., melting glaciers), can evoke grief, sadness, and feelings of loss in (place-based) solace. These emotions have previously been examined under the terms ecological grief (16) and solastalgia (92). Ecological grief is defined as "...the grief felt in relation to experienced or anticipated ecological losses, including the loss of species, ecosystems, and meaningful landscapes due to acute or chronic environmental change" [(16), p. 275]. Similarly, solastalgia refers to "...the pain or distress caused by the loss of, or inability to derive solace connected to the negatively perceived state of one's home environment" [(92), p. 96]. Ecological grief and solastalgia have been observed in various populations across the world, such as in the form of undermined notions of place-based, cultural, and self-identity; cumulative and chronic place-based distress; amplified mental health stressors; and heightened perceived risk of depression and suicide [e.g., (15, 93)]. In particular, individuals who live in close connection with nature, such as Indigenous people or farmers, have been found to be more vulnerable to the development of ecological grief and solastalgia $(16,92,94)$. These studies highlight the adverse mental health impact of "chronic" ecological events in the form of profound environmental changes.

\section{Impact of Increased Awareness}

A recent survey of over 27,000 participants from 26 countries revealed that climate change was perceived as a major international threat for half of the participating nations (95). This indicates an increase in the perception of the threat posed by climate change: while a median of $56 \%$ reported climate change to be a top threat in 2013, this number increased to $63 \%$ in 2017, and 67\% in 2018 (95). This perceived threat illustrates an indirect effect of climate change on mental health. For instance, a qualitative study with young urban children (10-12 years old) found that $82 \%$ reported feelings of sadness, fear, and anger in relation to environmental issues and $72 \%$ expressed pessimistic, negative, or apocalyptic views about the future (96). Furthermore, a poll conducted with 2,107 U.S. adults on the topic of climate change found that $56 \%$ identified climate change to be the most important problem of today's society, with $68 \%$ reporting having experienced at least a little eco-anxiety (97). Younger participants (18-34 years) were more affected, with almost half reporting climate change-related stress to have an impact on their daily lives (97).

Thus, far, vast differences exist in the definition of eco-anxiety, or climate (change) anxiety [e.g., (39, 98-100)]. This may be due to the fact that eco-anxiety can be understood quite differently from the varied perspectives of the respective disciplines (e.g., Sociology, Philosophy, or Depth-Psychology). Nowadays, some describe it as “... a specific form of anxiety relating to stress or distress caused by environmental changes and our knowledge of them" [(40), p. 1,233], while others use it to describe a range of negative climate emotions [e.g., (94)]. From the perspective of Clinical Psychology, eco-anxiety is understood as a syndrome, i.e., a set of psychological symptoms related to the broader spectrum of anxiety or fear that are triggered by (thoughts about) the climate and environmental crisis, which can cause subjective suffering and lead to functional impairments. The APA defines eco-anxiety as "... any anxiety or worry about climate change and its effects" [(97), para. 6]. From a clinical perspective, a defined set of criteria/symptoms for eco-/climate (change) anxiety do not yet exist. Instead, various symptoms have been linked to this particular anxiety, such as fear, distress, worry, sadness, or rumination (98). Currently, climate change anxiety can be assessed with a recently developed and validated measure by Clayton and Karazsia (99). It must be noted that responding to this unprecedented climate and environmental crisis with intense negative emotions is not a pathological reaction, but rather can be regarded as a normative, adequate, and justifiable response to a real existential threat [e.g., (16)]. However, if the eco-/climate 
(change) anxiety becomes maladaptive and so intense that it significantly impacts psychosocial functioning (i.e., interferes with everyday life functioning, causes profound suffering, or is perceived as uncontrollable), ecological syndromes such as ecoanxiety may become a clinically relevant concern warranting clinical attention (98).

Regarding this clinically relevant concern of the climate and environmental crisis, it is correct to state that the current diagnostic manuals, i.e., the DSM-5 (11), and the ICD-10 (12), do not include disorders such as eco-anxiety, climate-change phobia, prolonged eco-guilt disorder, or climate-change depression. However, it is a common misconception that is not possible to diagnose mental health disorders triggered by the climate and environmental crisis. In fact, the stressors associated with this crisis can theoretically cause a multitude of different mental health disorders, depending on the individual biopsychosocialvulnerability constellation of the affected person $(13,14)$. For instance, having constant worries about the state of the climate, the continuing deforestation of rainforests, the bee mortality, or the future perspectives of one's offspring, could provide the basis for the development of a Generalized Anxiety Disorder (DSM-5: 300.02; ICD-10: F41.1), if the symptomatology were to cause meaningful distress or significantly impact the psychosocial functioning. Furthermore, Adjustment Disorder (DSM-5: 309.9; ICD-10: F43.20) is defined as "... a maladaptive reaction to an identifiable psychosocial stressor or multiple stressors that usually emerges within a month after the onset of the stressor" [(101), p. S3]. This is a suitable and useful mental health diagnosis that can be used to describe a symptomatology of distress triggered by climate and environmental stressors. However, even if individuals did not meet the diagnostic criteria for an existing mental health disorder, the suffering caused by a subclinical/threshold symptomatology can also diminish quality of life and may warrant clinical attention.

\section{Impact of a Lack of Greenness and Contact With Nature}

Further evidence of the indirect effects of climate change on mental health can be seen in the rapidly ongoing trend toward urbanization, as more and more people lose contact with the natural world. The current discrepancy between the modern (urbanized) lifestyle and our psychophysiological development is thought to impact mental health. For example, the increased amygdala activity observed in city dwellers, compared to country or small-town dwellers, may be an indicator of the higher stress of city living (102). Furthermore, higher levels of urbanization have also been linked to increased psychopathology, such as psychosis and depression [e.g., (103)], and higher suicide rates (104). In addition, a recent large-scale cohort study investigated the relationship between environmental greenness and schizophrenia, using data from almost 870,000 individuals over a 10 years period (105). Results found that higher environmental greenness was associated with a lower schizophrenia incidence, suggesting that a lack of greenness may be one factor explaining why urban areas are linked to lower mental health (105).

\section{UNDERLYING PROCESSES}

Climate and environmental stressors can exert an impact on mental health through multiple pathways, five of which are presented in the following section:

\section{Biological Pathway}

In the following two sub-sections, the various physical health impacts are presented, followed by an in-depth description of psycho-pathophysiological processes induced by environmental toxins.

\section{Impact on Physical Health}

Given the intertwined relationship between physical and mental health [e.g., (106)], bodily harm by injuries or exposure to environmental toxins, as well as (infectious) illnesses, diseases, or physiological health conditions caused by climate and environmental stressors can increase the vulnerability for the development of mental ill-health. The impact of climate change on injury is not well-examined (107). However, existing data supports the notion that there is a link between changes in climate and the occurrence of injuries. Extreme weather events and natural disasters can increase the risk of injury. For instance, a systematic review on the impact of extreme weather events in developing countries reported an increase in injuries of 0.3$37.3 \%$ (65). Additionally, anomalously warmer temperatures, such heat waves, have been linked to an increase in deaths from unintentional injuries (e.g., falls) and intentional injuries [e.g., suicide, assault; (108)]. Heat stress was also significantly associated with an increased risk for work-related injuries, such as falls, stab-cut injuries, or road traffic injuries (109).

Heat waves have also been linked to a vast array of climatesensitive health outcomes, including communicable and noncommunicable diseases [e.g., $(110,111)]$. The human body tries to adapt to heat in a number of ways, such as by down-regulating thyroid hormones, up-regulating blood levels of noradrenaline and prolactin, and increasing heart rate [e.g., $(112,113)]$. Such heat stress can cause heat strain, hyperthermia, dehydration, heat-related exhaustion, heat syncope, heat cramps, and heatstroke [e.g., $(112,114)]$. While healthy individuals can be affected by heat-related illnesses [for a review see (115)]; being of higher age, taking certain medications, having a chronic disease (e.g., cardiovascular diseases, obesity, and diabetes), and having mental and neurological disorders (e.g., schizophrenia) are known risk conditions for heat-related illnesses (116-118).

Air pollution, which is exacerbated by warmer temperatures, is also a risk factor for a range of chronic diseases and medical conditions. Globally, air pollution has been shown to contribute to $29 \%$ of lung cancer deaths, $24 \%$ of stroke deaths, $25 \%$ of heart disease deaths, and $43 \%$ of lung disease deaths (50). While the impact of air pollutants has been extensively studied with respect to respiratory and cardiovascular diseases, it has also been more recently examined in connection to CNS related disorders, such as Alzheimer's and Parkinson's diseases (119).

Extreme weather events, such as heavy rainfalls and floods, can give rise to water-borne diseases, which are meaningful contributors to the global burden of disease and mortality 
(120). Examples of water-borne or water-related diseases include gastrointestinal diseases (e.g., diarrhea, cholera), typhoid fever, viral hepatitis, or schistosomiasis $(82,120,121)$. Such diseases are caused and fostered by multiple factors, including contaminated water, limited access to sanitation facilities, lack of knowledge about hygiene practices, shortage of electricity or plumbing, overcrowding, or malnutrition $(79,120,121)$. These diseases are a particular concern in developing countries, which, among other risk factors that limit adaptive capability (e.g., poverty), have a higher likelihood to be severely affected by extreme weather events (121).

Vector-borne diseases are illnesses transmitted through the bite of vectors (e.g., mosquitos, ticks), whose presence and abundance are climate sensitive $(122,123)$. These diseases include West Nile Fever, Lyme borreliosis, tickborne encephalitis, lupus, malaria, and dengue fever; and they have been linked to climate change-related alterations in regional and local climatic and environmental conditions (79, 122-124). The increase in vector-borne (and zoonotic) diseases is a consequences of several (interacting) mechanisms, including changes in the geographical distribution range and the population density of hosts and vectors, and changes in infection prevalence and pathogen load (development, reproduction, and replication) (124).

\section{Pathophysiological Processes Induced by Environmental Toxins}

Environmental toxins in the form of air pollution can be translated into psychopathology via biological pathways, due to their toxic effect on the CNS $(85,89)$. In this pathway, (long-term) exposure to environmental toxicants in the air [e.g., (ultra)fine particulate matter, nitrogen oxides, and heavy metals] has been linked to environmentally-induced oxidative stress, neuroinflammation, damage to the cerebrovascular system, and neurodegenerative pathology $(88,89,91)$. Previous studies have shown that components of air pollution particles can reach the brain via different routes. For example, particulate matter and absorbed and soluble compounds can enter the brain directly, with consequences including neuroinflammation, microglial activation, and blood-brain barrier damage or dysfunction (89). Furthermore, a more indirect route is peripheral inflammation, which is disinhibited as a consequence of the peripheral presence of pollutants. This can exert further negative effects on the brain by circulating inflammatory cytokines (125). Together, these processes stimulate neuropathology and diseases of the CNS.

In addition, the disinhibition of peripheral inflammation can have negative long-term effects on somatic health. Inflammatory mechanisms are directly, and often causally, involved in many pathophysiological processes, such as atherosclerosis, insulin resistance, and the development of malignancies (126). Through these mechanisms, inflammation contributes to life-threatening diseases, such as cardiovascular disease, type 2 diabetes, some types of cancer, and sarcopenia [e.g., $(127,128)]$; Inflammation can also have adverse mental health effects, including the development of depressive symptoms, fatigue, and long-term cognitive decline $(125,129)$.

\section{Emotional Pathway}

The (topic of) climate change, pollution, and the destruction of the natural environment can impact mental health by evoking intensely negative emotions (98). This potential to induce negative emotional responses is detailed in the following sections, followed by a description of an underlying process through which triggered emotional responses can detrimentally impact mental health.

\section{An Emotional Topic}

The climate and environmental crisis can be understood as a severe, and rather unique current (global) stressor, which is associated with particular aspects that evoke or intensify negative emotional responses. The fact that the existence of humankind may be threatened by the consequences of this crisis links it to themes such as existential threat, destruction, or death [e.g., (39)]. These morbid associations can induce mortality awareness, which "...creates an existential terror" that can engage psychological defenses and provoke profoundly distressing emotional reactions [(130), p. 3]. The global scale of the crisis can further give rise to feelings of apathy, numbness, loss of control, powerlessness, uncertainties about the future, as well as a state of "eco-paralysis," particularly in young people $(41,94)$. These feelings can be further exacerbated by observing the apparent inaction by global leaders and the general public to mitigate or adequately address the crisis. In addition, the impact of the climate and environmental crisis is unequally distributed across the globe, often most affecting those who contributed least $(131,132)$. This issue of injustice is a component of the crisis that has the potential to induce strong emotional reactions, including anger, and (ecological) guilt (133).

Furthermore, human-created/technological disasters and interpersonal traumatic experiences have commonly been linked to worse mental health outcomes in comparison to natural disasters, such as volcanic eruptions [e.g., (70)]. However, extreme weather events are more common and intense due to the magnitude of the anthropogenic climate change. This adds a human-created component to these events and blurs the division between natural and human-created disasters (58). The growing awareness of the anthropogenic aspect to climate change and related consequences, as well as the obvious human-created elements of pollution and the destruction of the environment, may have negative effects on mental health (59).

Lastly, the natural world bears an emotional importance for human beings (45). According to Wilson's Biophilia Hypothesis (134), humans have an inherent emotional affiliation to the natural world, and "... an innate tendency to focus on life and lifelike processes" [(30), p. 1]. Individuals living in close connection to the natural world can experience this bond to nature as similar to that with a person. For example, in interview research with Inuit in Canada, one participant reported that “...nature's about, to us is like in a way, another person" [(135), p. 19]. Observing the pollution and destruction of the natural world can thus psychologically hurt individuals, induce feelings of distress, and trigger emotional misery, particularly in those with close bonds to nature. 


\section{From Negative Emotions and Distress to III-Health}

Longer-term experiences of stress, anxiety, or depression are associated with altered basal activity of the main stress systems: the sympathetic nervous system (SNS) and the hypothalamuspituitary-adrenal axis (HPA axis). The SNS tends to be overactivated in individuals experiencing chronic stress, anxiety, or depression, which is reflected by higher plasma concentrations of epinephrine and norepinephrine, and is typically associated with increased blood pressure, heart rate, and other sympathetically controlled functions (136). The HPA axis mainly shows alterations in its diurnal rhythm in response to stress, with the specific changes depending on the duration and type of stressor. For instance, for chronic stressors with a duration of several months, the majority of studies report a flattened diurnal activity rhythm and markedly lower plasma cortisol concentrations, a state called hypocortisolism $(137,138)$. Alterations in these two stress systems converge in their effect on dependent systems to become a threat to health. One important dependent system is the inflammatory system, which can be regulated by stress systems, with the SNS typically exerting a stimulating effect on inflammatory mechanisms and the HPA axis exerting antiinflammatory effects [for example see (139)]. Such stress-related alterations (i.e., over-active SNS, under-active HPA axis), result in over-stimulation or disinhibition of inflammatory pathways and have typically been found in states of anxiety, depression, and stress $(140,141)$.

Through the pathway of inflammation, psychological and environmental effects can converge to negatively affect mental and physical health (142). In the context of climate change, psychological and environmental effects can negatively affect brain and periphery, not only in an additive, but also in a mutually potentiating way. For example, pollutant-induced weakening of the blood-brain barrier (89) would make it significantly easier for inflammatory cytokines-which can be the result of pollutants and/or psychological stressto enter the brain. This can potentiate immune-to-brain signaling and thereby increase the development of further sickness-related psychological symptoms. A vicious cycle can develop, particularly in some vulnerable populations, with severe consequences for mental and physical health [see (142)].

\section{Cognitive Pathway}

Climate and environmental stressors can impact mental health through their potential to influence key self-concepts and to induce non-adaptive cognitive defense mechanisms and coping strategies. These components of the cognitive pathway are detailed in the following sections.

\section{Feelings of Identity}

Humans can establish emotional bonds with their local environment. People-place bonds serve a functional purpose in the fulfillment of needs linked to solace, security, belonging, self-esteem, and identity (93). These people-place bonds and associated needs are threatened due to acute changes in the environment by natural disasters, or gradual changes that are either human-created or a consequence of climate change. This particularly affects individuals that live in close connection to the natural world, such as Indigenous populations, or those whose work and livelihoods largely depend on farmland (93). For instance, the Inuit of Northern Canada have a close connection to the land, and the changing environment has impacted their traditional way of living and induced profound changes in how they see and understand themselves. For example, in interviews they reported that "...it's who they are, it's what they've been grown up doing. And their parents have been doing it forever, so I mean they're kind of losing a sense of who they are" [(135), p. 20]; or that "...Inuit are people of the sea ice. If there is no more sea ice, how can we be people of the sea ice?" [Attutauniujut Nunami/Lament for the Land; www.lamentfortheland.ca; found in (16), p. 277]. This profound impact on the land, their way of living, and their perceived identity can elicit feelings of despair and even foster mental health issues. For example, research by Kumar and Tjepkema (143) found that the suicide rate was nine times higher for Inuit (72.3 suicides per 100,000 person-years at risk) than for non-Indigenous people ( 8.0 suicides per 100,000 person-years at risk). The Inuit, who have close connections to the land, are confronted by multiple stressors, among which is the climate and environmental crisis.

\section{Cognitive Defense Mechanisms and Coping Strategies}

Defense mechanisms and coping strategies, such as emotional-, cognitive-, or meaning-focused coping, positive reappraisal, or trust, can help individuals to deal with the unpleasant, undesirable, or unacceptable emotional states and thoughts elicited by the climate and environmental crisis. These mechanisms and strategies can also assist in creating feelings of constructive, active hope, as well as empowerment $(39,41)$. However, despite the known dangers of the climate and environmental crisis, resistance still exists against urgently needed mitigation activities. Explanations for this include the complex and abstract nature of climate change that is difficult to understand, visualize, and communicate; issues dealing with uncertainties; temporal discounting (i.e., placing a different value on short-term vs. long-term rewards); group dynamic processes (e.g., collective ignorance); or lack of personal relevance resulting in lack of urgency to act [e.g., (7)]. This is described in the Giddens Paradox: "It states that, since the dangers posed by global warming aren't tangible, immediate or visible in the course of day-to-day life-however awesome they may appear-many will sit on their hands and do nothing concrete about them. Yet waiting until they become visible and acute before being stirred to serious action will, by definition, be too late" [(144), p. 2].

Denial of the reality of climate change is a frequently observed cognitive response, particularly in conservative white males, conservative think tanks, or religious individuals $(145,146)$. This denial can be evoked for various reasons, including by mortality awareness, cognitive dissonance, protection of selfand group-identity and social norms, or system justification (145, 147, 148). The Terror Management Theory [TMT, (149)] offers one explanation for why the climate and environmental crisis can lead to strong denial responses in some individuals. The TMT states that the cognitive ability of self-awareness is coupled with the awareness of one's own mortality (130). Cognitive 
defense mechanisms can be engaged to deal with the thoughts of mortality elicited by the climate and environmental crisis: “... accessible death thoughts activate proximal defenses, for example, suppressing death-related thoughts via distraction or rationalization, or pushing the problem of death into the distant future and denying one's vulnerability. Cognitively inaccessible death thoughts activate distal defenses, for example, maintaining self-esteem and faith in one's cultural worldview" [(130), p. 3, 4].

Denial can also be a consequence of cognitive dissonance (147). Knowing that immediate global action is required calls for behavioral changes, which can be daunting and also hindered by various barriers, such as unwillingness to give up a comfortable lifestyle $(41,147)$. The conflict between being informed about the crisis and being unwilling or unable to take mitigating actions can create cognitive dissonance, which can be solved using denial mechanisms, such as rejection of blame or responsibility, or condemning the accuser (147). Furthermore, denial on a political level (by politicians) can provide false hope that there is no problem or threat, which can reinforce the belief that there is no reason for negative feelings [see (39)]. The complex and abstract nature of climate change, coupled with cognitive coping strategies can help explain the observed inaction toward the climate and environmental crisis.

\section{Behavioral Pathway}

Climate and environmental stressors can also impact mental health via health-related behaviors. Health-damaging behaviors are often maladaptive responses to facilitate coping with (overwhelming) negative emotions and affective states (e.g., anger, fear), or unfavorable or harmful circumstances and environments [e.g., (150)]. An example of one health-damaging behavior is lack of physical activity, which has been associated with food insecurity (84), air pollution (86), and lower exposure to greenspace (151). In contrast, being surrounded by greenness has been shown to foster physical activity, which may positively impact weight and health [e.g., (152, 153)]. Surrounding greenspace has also been found to facilitate social cohesion (154). Both (outdoor) physical activities and positive social interactions and social cohesion have repeatedly been linked to beneficial impacts on mental health [e.g., (155-158)].

Another health-related behavior that is affected by climate change is sleep behavior (i.e., sleep time and quality), which can be impacted by heat $(72,159)$. Given the importance of a healthy sleep pattern for good mental health [e.g., (160)], this is an important pathway to consider in the understanding of how an ecological stressor (i.e., heat) can translate into poorer mental health.

Criminal activity and violence is a further set of behaviors that has previously been linked to changes and shifts in climate and weather and that has potential to affect physical and mental health. A study conducted in California that investigated the impact of drought on state-level rates of crime over an extended period of time found a meaningful increase in property (but not violent) crimes (161). A recently published study that analyzed survey data encompassing information from 80,000 women living in sub-Saharan Africa found that drought was linked to intimate partner violence, particularly in female adolescents and jobless women (162).

\section{Social Pathway}

Given the impact of the climate and environmental crisis on multiple aspects of social life and socio-economic factors, combined with the fact that social determinants are meaningfully related to mental health (163), the social pathway is a key translator of climate and environmental stressors into mental health effects [e.g., (5)].

\section{Destabilization of Social Relationships and Social Networks}

Humankind is a social species and positive social interactions and social support are crucial for mental health, as they constitute important protective forces against the development of various mental health disorders, particularly PTSD (164). Climate and environmental stressors can destabilize social networks, interrupt social support chains, and reduce social cohesion. For example, food insecurity has been shown to lead to hopelessness and low levels of self-efficacy, which destabilized social relationships and increased the risk for depression (84). Furthermore, changes in urban social behavior have been observed as a result of air pollution, such as interacting less with neighbors (i.e., lower "social reciprocity"), which has been linked to depressive symptomatology (86). These studies illustrate the detrimental effect of the climate and environmental crisis on both social and mental health.

\section{Impact on Socio-Economic Factors}

Climate change, pollution, and destruction of the environment can impair an individuals' socio-economic status, and ultimately their mental health, by interrupting salary payments or education, loss of employment, financial constraints due to reduced agricultural production, crop failure, loss of livelihoods, or migration (131). For example, long-lasting heat waves and droughts have been shown to influence socio-economic hardship through the impact on work capacity, labor productivity, livelihoods, agricultural production, and food and water security (165). The complexity of this pathway is illustrated in a systematic review by Vins et al. (166) on the long-term mental health impact of drought. Drawing on data from 82 articles, the authors created a causal process diagram depicting the multiple indirect and interacting pathways between droughts and mental health. Drought was found to have multiple economic impacts, particularly for those dependent on weather conditions for their livelihood (e.g., farmers), which can result in financial hardship and endanger food security. This in turn can lead to stress, social isolation, interruption of education, worries about the future, denial, intimate partner violence, substance abuse, feelings of shame, depression, or suicide. This impact of drought (and the related economic effects) on mental health was shown to have a dose-response relationship, i.e., the more severe the drought, the worse the psychopathological consequences (166).

In connection to the economic effects, drought-related migration was further identified as having an important influence on mental health. The large-scale migration, resettlement, 
and displacement of people and populations are and will become necessary in response to the unfolding climate and environmental crisis, as a result of depressed economies and decreased environmental resources, such as food or water (166). This has the potential for a multitude of problematic social consequences, including disrupted social networks, loss of (landbound) cultural traditions, acculturation stress, social turmoil, civil and international conflicts, and even wars (166-168). Regions of the world that struggle with corrupt political systems and social inequality are at higher risk of being affected by these developments (38). This research highlights the far-reaching socio-economic and related psychosocial health impacts of the climate and environmental crisis.

\section{VULNERABILITY AND ADAPTATION}

If the current rate of climate and environmental change is maintained, an overall increase in the adverse mental health impacts can be expected. However, individuals differ with respect to their vulnerability to ecological stressors, with the highest levels of vulnerability seen in those with pre-existing conditions (e.g., physical illnesses), higher exposure to ecological stressors, and reduced access to resources [e.g., $(61,113,158)]$. The following sections will describe risk and vulnerability factors, including vulnerable populations, as well as factors with the potential for increased adaptation in the face of climate and environmental stressors.

\section{Vulnerability}

The climate and environmental crisis further increases existing inequalities by disproportionally affecting marginalized groups that are inherently vulnerable, for example, due to their development status (e.g., children), socio-economic disadvantage, or having mental health issues [e.g., (8)]. Such vulnerabilities do not act in isolation, but rather interact with each other. For instance, Indigenous people often live in geographical regions prone to extreme weather events, and typically have lower socio-economic resources and social power (7). Such economic, social, and gender inequalities are also risk factors for the development of psychopathology, and the added impact of climate and environmental stressors can lead to worse mental health $(38,132,163)$.

\section{Risk by Exposure}

A differential impact on mental health is expected as a function of the magnitude of exposure to ecological stressors, with greater (peri- and post-) disaster exposure resulting in more adverse mental health effects $(66,67,84,169)$. For instance, high disaster exposure (as assessed by magnitude of disaster, property loss, witnessing someone dying, risk of own death, casualties, physical injuries, food/clothing insecurity, violence, or practical problems) has been shown to be a relevant risk factor for the development of (probable) PTSD $(65,70,170,171)$.

Exposure to the climate and environmental crisis is unequally distributed across the globe as a function of geographical regions that are more or less prone and sensitive to ecological stressors. More susceptible populations include those living in and dependent on rural landscapes (e.g., farming populations), in regions of dryland, in areas prone to floods, and in remote areas $(48,76)$. This vulnerability can be due to the geographical and social isolation, reduced infrastructure, lower levels of economic resources, or transport options (172). Developing countries, and particularly regions of the Global South, are also more vulnerable as they are more affected by water insecurity, steadily growing populations, increasing urbanization, and ever-present poverty $(82,120,121,132)$. Populations in urban regions are also exposed to ecological stressors, with a higher exposure to air pollution (85), as well as higher day- and night-time temperatures caused by a lack of (green) vegetation, dense architecture, and a higher temperature absorbance by urban surfaces (173). Urban residents are also exposed to more extreme weather events (e.g., thunderstorms) as urban areas intensify such weather events, combined with the fact that cities are often located close to water (i.e., rivers, sea), which increases the likelihood for floods (79). Additionally, urban life can be a stressful environment in itself, due to overpopulation, noise, crime, social stress, loneliness, and lower social support $(85,174)$. This differential exposure to climate and environmental stressors can render vulnerable individuals more susceptible to various physical and mental health conditions.

\section{Indigenous People}

Indigenous communities, particularly those living in remote areas, have a higher vulnerability to the climate and environmental crisis $(166,172)$. This includes individuals living in regions of the North (e.g., Inuit in Canada) who are (among other factors) affected by melting ice and alterations in flora and fauna; as well as Indigenous Australians who are affected by heat waves and bushfires $(15,172)$. The elevated vulnerability of Indigenous communities is due to their close dependence on and bond with nature for living, culture, and spirituality (48). Other vulnerability factors include susceptibility to poverty, a higher disease burden, low quality of infrastructure, and geographical remoteness that limits access to health-related (emergency) services (172).

\section{Children and Adolescents}

Minors are particularly vulnerable to the health impacts of the climate and environmental crisis: "According to the limited results from WHO, children under 5 years of age suffer the most from the consequences of climate change, with 88 percent of lost DALYs (disability-adjusted life years) attributable to climate change occurring in this age group in both developed and developing countries." [(175), p. 33]. Ecological stressors can directly impact children and adolescents, for example, through natural disasters, via water-borne diseases, or air pollution. For instance, research on air pollution found that adolescents were vulnerable to the development of respiratory conditions in response to environmental toxins [e.g., (176)]; with other studies reporting evidence of cognitive dysfunction, damage in the prefrontal cortex area, or slower maturation [for a short review see (90)]. Such health impacts can affect the mental health of children and adolescents by interacting with existing mental health issues or by causing psychological sequelae (59, 
177). Ecological stressors can also indirectly impact children and adolescents, such as through climate-related socio-economic hardship or migration (59); or through a lack of greenness exposure during early development, which has been linked to lower visuo-motor and language development [for a review see (151)].

Several explanations can be attributed to the increased vulnerability of minors. A major factor is that of the 2.2 billion children living worldwide, 1.9 billion are living in developing countries (178), many of which are disproportionally affected by ecological stressors. Another major risk factor is the biopsychological developmental phase. Children and adolescents have an underdeveloped physiology, limited cognitive and emotional abilities to deal with stressful circumstances, and are dependent on others [e.g., (74)]. As a consequence of these aspects of the biopsychological developmental phase, children and adolescents have a heightened vulnerability to stress. Stress experiences during childhood and/or adolescence can impact the brain structures and functions of the affected minors (179). This can impact their psychological development (e.g., emotion regulation issues, poorer cognitive abilities, learning and adjustment issues, or behavioral disorders) and increase their vulnerability to future stress experiences (74).

\section{Older Adults}

Older individuals are more vulnerable to climate and environmental stressors. For example, due to decreased mobility, functional limitations, increased frailty, and multimorbidity, older adults have a decreased likelihood to escape and survive (injuries from) disasters [e.g., (180)]. This can be seen in the age-bias of the fatalities from Hurricane Katrina: almost $50 \%$ of the deceased were older than 75 years, and up to $85 \%$ were older than 51 years (181). Older age was also found to be a meaningful predictor of higher posttraumatic stress after Hurricane Sandy (171). In addition, older individuals have a higher risk for the development of depression in response to climate change-related food insecurity (84).

Older adults are also more susceptible to extreme heat events (116). For example, research has linked warmer temperatures to higher suicide rates in older adults (182). Several explanations can account for the higher heat-related morbidity and mortality in older individuals: First, older individuals have a decreased physiological ability for thermoregulation, as well as the ability to sense, respond to, and recover from dehydration $(116,173)$. Second, higher age is linked to a higher prevalence for chronic health conditions, which can compound heat-related illnesses. Third, older adults have more heat-related risk factors, such as living alone, or smaller social networks $(116,173)$. Together, these aspects can increase older adults' vulnerability to (heat-related) ecological stressors.

\section{Female Gender, i.e., Those Who Identify as Female}

Women are considered to be more vulnerable to the effects of the climate and environmental crisis: "Climate change acts as a threat multiplier on already existing issues associated with gender inequality to increase the problem of marginalization faced by women" [(183), p. 2]. The reasons for this vulnerability vary depending on region and culture. In Europe, for instance, the higher vulnerability for women can be understood in relation to the increased likelihood of heat wave related fatalities in women [for a review see (115)]. In developing countries, the higher vulnerability can be linked to the structural disadvantages faced by many women, such as limited financial resources, and livelihoods that are largely dependent on the climate. The differential susceptibility of men and women can also be understood in relation to gender roles and discrimination in patriarchal societies, which can increase the risk exposure for women (183). For example, in many developing countries, fetching water is a physically straining task often carried out by children, girls, and women. This task is associated with many health risks, including falls, injuries, pain, fatigue, and a general lower well-being (82). It can be additionally dangerous due to a heightened risk for the sexual assault of females on the way to fetch water [for a review see (83)]. These factors can increase women's vulnerability to climate and environmental stressors.

\section{Pre-existing Physical and Mental Health Conditions}

Individuals at higher risk to be affected by the climate and environmental crisis (i.e., to present with psychopathology), include those with pre-existing health conditions and disabilities, those with higher stress levels or previous exposure to traumata, and those relying on (psychotropic) medication [e.g., (171)]. Individuals with (chronic) physical health conditions, such as cardiovascular or respiratory diseases or obesity, have a higher risk for heat-related morbidity and mortality, due to altered thermoregulation $(116,173)$. In addition, individuals with disorders that interfere with behavior, mobility, and/or awareness (e.g., dementia, Parkinson's disease) also have a higher risk for heat-related mortality (115). Furthermore, pre-existing mental health conditions can increase susceptibility to the impact of extreme weather events, such as an increased likelihood for PTSD (65). However, evidence on this is mixed. For example, in the study of estimated PTSD following Hurricane Katrina, no relationship was found between pre-existing psychopathology and PTSD trajectories (62). Certain medications can also affect thermoregulation or thirst-regulation (117, 118, 173). For instance, research on the 2003 heat wave in France revealed that anticholinergic, antipsychotic, and anxiolytic drugs were independently linked to hospitalization during the heat wave. This may be due to the detrimental impact of these medications on physiological thermoregulation (e.g., inhibited sweating) and behavioral thermoregulation (e.g., reduced water intake-drinking behavior) (184). This highlights the increased vulnerability to the impact of ecological stressors for individuals with pre-existing physical and mental health conditions.

\section{Low Socio-Economic Status}

Individuals with lower socio-economic resources, i.e., those with lower income, social status, or educational attainment, are more vulnerable to climate and environmental stressors $(79,165)$. For example, low-wage and extremely poor urban residents who have no or very limited isolation, as is the case in slums, are more strongly affected by heat or heavy rain (79). Low-income and education are also linked to a higher heat-related mortality risk 
[for a review see (116)]. Furthermore, increasing temperatures can cause heat stress and decrease work productivity and increase the likelihood for injury, which disproportionally affects countries with warmer climates. For example, a national cohort study in Thailand with almost 60,000 workers, showed that onefifth of the workers reported occupation-related heat stress and that this was meaningfully linked to a higher risk of injuries (109). In addition, individuals with disadvantaged backgrounds often live in areas with reduced access to green spaces and lower tree canopy cover, with decreased exposure to the health-promoting influence of greenness [e.g., (157)]. These multi-faceted aspects of low socio-economic status can increase vulnerability to the impact of the climate and environmental crisis.

\section{Adaptation}

There is a repeatedly observed, yet insufficiently understood heterogeneity in how individuals respond and adapt to adversity. While it is essential to consider risk and vulnerability factors in explaining this heterogeneity, protective factors are equally as important in understanding interindividual differences in adapting to the climate and environmental crisis and the impact on mental health. This positive adaptation and potential protective factors will be outlined in the following sections.

\section{Resilience}

Resilience can be broadly defined as positive adaptation in the face or aftermath of stress and adversity [e.g., (185)]. Resilience is not an uncommon phenomenon and with respect to acute disasters, it has been shown that the majority of individuals can adapt well (22). For example, longitudinal research by Lowe and Rhodes (169) found that more than 60\% of participants showed a resilient trajectory after Hurricane Katrina. Another longitudinal study with Mexican individuals affected by a largescale flood found that $35 \%$ of participants showed a resistant trajectory (stable, mild symptomatology), and 31\% showed a resilient trajectory (initial severe symptomology that declined to a moderate symptom level) (186). Evidence of resilience may also be seen for gradual changes to the natural environment, such as that experienced by the Inuit in Canada: “... there is nothing else (we can do), we can't dwell on it. Then we would be all suicidal. You just have to do the best you can with what change is coming" [(15), p. 265]. Such resilience varies as a function of internal and external factors [e.g., (187)].

Internal psychological factors that have been linked to higher adaptability to the climate and environmental crisis include selfefficacy (188), sense of optimism, being informed, social support $(63,169)$, and increased (access to) pre-disaster resources (189). In climate scientists, a source of resilience can be seen in the sense of community, i.e., the feeling that one is not alone in combating the climate change but that one is working in a community with a shared goal; this can assist in increasing the perception of being supported and validated (190).

External resilience factors include the general resilience of communities, as well as specific aspects, such as how prepared the health-care sector is to handle disasters and environmental risks (68). An important external factor is vicinity or exposure to surrounding greenness and outdoor blue spaces, such as lakes (105, 191, 192). A large and steadily increasing number of studies demonstrate the health-promoting effects of being in and interacting with nature [e.g., $(153,154)]$, of viewing natural landscapes [e.g., (193)], or even listing to natural sounds [e.g., (194)]. Increased exposure to environmental greenness has been linked to lower psychological distress, depression and anxiety disorders, and schizophrenia incidence (105, 157, 195); as well as to slower cognitive decline in middle-aged individuals (191); and improved self-reported mental health in urban settings [see (196)]. Greenness is also important for healthy development in children, with a recent systematic review identifying an association between exposure to greenness and decreased emotional and behavioral difficulties, particularly inattention and hyperactivity (151). Furthermore, surrounding greenness can decrease the ambient and surface temperature in cities, and thus counteract the negative health effects of urban heat (105). Greenspace has also been found to physically reduce exposure to (traffic) noise and to buffer the noise-induced psychological stress response (154).

The positive impact of nature on emotional well-being has also been observed for Indigenous people who have close bonds with the land. For example, research with Inuit in Canada found that if they were unable to be outside and interact with nature, participants reported feelings of craving and being caged inside like an animal, which was stressful and depressing $(15,135)$. In contrast, being closely connected to nature elicited positive emotions and increased the feeling of being healthy. For instance, one participant reported that "...the air and the land takes a lot of your feelings away and replaces the negative energy with the positive energy, nature ...” [(15), p. 262]. The above research suggests that certain (internal and external) factors can foster positive adaptation (i.e., resilience) to climate and environmental stressors.

\section{Adversity-Related Positive Development}

Some individuals may not only adapt well in the face of adversity, but may also experience positive interpersonal development [e.g., (197)]. An example of this can be seen in the research on Hurricane Katrina (198). Results not only showed a significantly lower conditional prevalence of suicidality post-hurricane (suicidal ideation: $0.7 \%$; suicidal plans: $0.4 \%$ ), compared pre-hurricane (suicidal ideation: $8.4 \%$; suicidal plans: $3.6 \%$ ); but also revealed that suicidality was linked to aspects of posttraumatic growth, such as becoming aware of one's inner strength or developing faith in the capability to rebuild one's life (198). Another example is provided by a recent qualitative study that involved interviews on lived experiences by individuals who were personally affected by severe wildfires in Canada: It was found that besides negative feelings of distress, anxiety and uncertainty by their evacuation and isolation, positive aspects were reported, too, such as the creation of opportunities for supporting and caring for one another (61).

Taken together, the above research indicates that while it is important to consider risk and vulnerability to ecological stressors, protective factors can also facilitate positive adaptation and even development in response to the climate and environmental crisis. 


\section{METHODOLOGICAL CONSIDERATIONS AND FUTURE DIRECTIONS}

In the exploration of the literature on climate change and mental health, methodological limitations must also be considered to inform directions for future research.

\section{Methodological Limitations}

Given the vast complexities of the two factors involved (i.e., anthropogenic climate change and mental health), attributing a causal link is difficult and poses multiple methodological challenges (22). While an increasing number of studies have examined the adverse mental health effects of the climate and environmental crisis, much of the available data is based on (retrospective) cross-sectional research, or qualitative, case-study and ethnographic designs. These studies lack information on trajectories and long-term effects and prohibit the establishment of causal connections (83). Baseline data (i.e., pre-disaster mental functioning) is often lacking [valuable exceptions are (63, 64, 66)]. This hinders statements about change in psychopathology in response to the event, as well as the examination of predictors related to interindividual variability in adaptation (199). The mental health impact of acute, isolated events (e.g., hurricanes) can be more easily assessed, such as by examining the change in mental functioning prior- (if available) to post-disaster. However, the attribution of (all) these extreme weather events to climate change is problematic; as while their increased frequency or power may vary as a function of the changing climate, their occurrence may not $(8,131)$. Attributing the mental health impact of sub-acute and chronic phenomena is also challenging, as they often do not have a defined beginning or ending and their impact is often experienced indirectly due to the subtle, gradually-evolving, and accumulating nature of these types of events (8).

With regard to mental health, the majority of studies assessed mental health disorders with self-report screening instruments, which are prone to subjective bias, are less precise than structured clinical interviews, and limit conclusions to probable/estimated mental health disorders. In addition, many studies did not include control groups, or neglected to control for relevant confounding influences $(67,85)$. It should also be taken into consideration that mental health disorders can vary as a function of norms and cultural contexts and their etiology depends on multiple biopsychosocial factors (11). Furthermore, the assessment of adverse mental health effects in post-disaster populations is often affected by sample biases. For example, those who are most marginalized, those affected most by (post)disasterrelated stressors, and those with the highest psychopathological burden are less likely to participate in studies, which bears the potential for underestimation of mental health effects $(62,170)$. Mental health disorders are also stigmatized in many cultures, which can impact disclosure and assessment (200).

\section{Recommendations for Future Studies}

In addition to addressing these methodological limitations identified in previous studies, some specific recommendations should also be considered for future research. A stronger focus should be placed on underlying processes, particularly emotional, cognitive, and behavioral processes that have previously been neglected. Future studies should also examine potential positive changes that can occur as a result of the climate and environmental crisis, such as post-disaster psychological growth; increased sense of meaning, social engagement, and social cohesion compassion; or increased engagement with mitigation activities $(8,38,198)$.

Going forward, mixed-methods approaches are recommended, as they combine qualitative and quantitative methods that are suitable to assess complex relationships, such as the adverse mental health impact of sub-acute weather events (166). Mixed-methods also allow for a person-centered approach and an in-depth analyses and understanding of rich data, as well as the quantification of the mental health burden (67). There is also a need to move beyond the current focus of conventional epidemiology, which "...focuses too much on the individual, on direct or proximate causes, on the past and present, and on current states of being; and too little on whole populations, indirect and distal influences, the life course and the future, and the dynamics of health across contexts" [(131), p. 283]. Future research could apply a systems approach (i.e., combining various perspectives from multiple academic disciplines and perspectives) to better foster an understanding of the intertwined factors and processes underpinning climate change and mental health [see (131)]. With regard to data assessment analysis methods, large-scale, longitudinal, population health studies and experimental epidemiological studies could best fit this approach, using network- and data-driven analyses, as well as agent-based and dynamic models (131).

\section{CONCLUSION}

Climate change is not only one of this century's major challenges, but is probably one of the most important challenges in the history of humankind. Given the dependence of humans on a healthy environment (124), the mitigation of climate change and protection of the natural environment must become a top priority. A change toward the responsible management and protection of the natural world and a more sustainable lifestyle may ultimately foster better mental health [e.g., (5)]: "The good news is that such transformative change, with social and economic justice for all, promises far greater human well-being than does business as usual" [(3), p. 11].

A growing number of studies are examining the mental health impact of the anthropogenic climate change, pollution, and destruction of the natural environment. However, the climate and environmental crisis, as well as mental health, are highly complex topics; and as this field of study is still in its early days, the underlying processes remain insufficiently understood. This synergy of literature has aimed to provide a current summary of existing research on the mental health impact of the climate and environmental crisis from the perspective of clinical psychology. Given the urgency of the current situation, it is of crucial importance that future research 
examines this neglected relationship in light of the identified processes and pathways, including the consideration of potential vulnerability and protective factors. We herewith call for increased investigations into this topic by clinical psychologists, within the context of this rapidly growing research area of Clinical Ecopsychology.

\section{REFERENCES}

1. Crutzen PJ. The "anthropocene". in Ehlers E, Krafft T, editors, Earth System Science in the Anthropocene. Berlin, Heidelberg: Springer (2006). p. 1318. doi: 10.1007/3-540-26590-2_3

2. Oldfield F, Barnosky AD, Dearing J, Fischer-Kowalski M, McNeill J, Steffen $\mathrm{W}$, et al. The anthropocene review: its significance, implications and the rationale for a new transdisciplinary journal. Anhropocene Rev. (2014) 1:37. doi: 10.1177/2053019613500445

3. Ripple WJ, Wolf C, Newsome TM, Barnard P, Moomaw WR. World scientists' warning of a climate emergency. Bioscience. (2020) 70:100. doi: 10.1093/biosci/biz152

4. Costello A, Abbas M, Allen A, Ball S, Bell S, Bellamy R, et al. Managing the health effects of climate change: lancet and University College London Institute for Global Health Commission. Lancet. (2009) 373:1693733. doi: 10.1016/S0140-6736(09)60935-1

5. Berry HL, Bowen K, Kjellstrom T. Climate change and mental health: a causal pathways framework. Int J Public Health. (2010) 55:12332. doi: 10.1007/s00038-009-0112-0

6. Cianconi P, Betro S, Janiri L. The impact of climate change on mental health: a systematic descriptive review. Front Psychiatry. (2020) 11:74. doi: 10.3389/fpsyt.2020.00074

7. Clayton, S. Psychology and climate change. Curr Biol. (2019) 29:R9925. doi: 10.1016/j.cub.2019.07.017

8. Hayes K, Blashki G, Wiseman J, Burke S, Reifels L. Climate change and mental health: risks, impacts and priority actions. Int J Ment Health Syst. (2018) 12:6. doi: 10.1186/s13033-018-0210-6

9. Palinkas LA, Wong M. Global climate change and mental health. Curr Opin Psychol. (2020) 32:12-6. doi: 10.1016/j.copsyc.2019. 06.023

10. American Psychological Association. Clinical Psychology. (2008). Available online at: https://www.apa.org/ed/graduate/specialize/clinical (accessed April 16, 2021).

11. American Psychiatric Association. Diagnostic and statistical manual of mental disorders. 5th ed. Arlington, VA: Author. (2013). doi: 10.1176/appi.books.9780890425596

12. World Health Organization. The ICD-10 Classification of Mental and Behavioural Disorders: Clinical Descriptions and Diagnostic Guidelines. Geneva: World Health Organization (1992).

13. Adler RH. Engel's biopsychosocial model is still relevant today. $J$ Psychosom Res. (2009) 67:607-11. doi: 10.1016/j.jpsychores.2009. 08.008

14. Engel GL. The need for a new medical model: a challenge for biomedicine. Science. (1977) 196:129-36. doi: 10.1126/science.847460

15. Cunsolo Willox AC, Harper SL, Ford JD, Edge VL, Landman K, Houle $\mathrm{K}$, et al. Climate change and mental health: an exploratory case study from Rigolet, Nunatsiavut, Canada. Climatic Change. (2013) 121:25570. doi: 10.1007/s10584-013-0875-4

16. Cunsolo A, Ellis NR. Ecological grief as a mental health response to climate change-related loss. Nat Clim Chang. (2018) 8:275-81. doi: 10.1038/s41558-018-0092-2

17. Kirmayer LJ, Gómez-Carrillo A. Culturally responsive clinical psychology and psychiatry: an ecosocial approach. In: Maercker A, Heim E, Kirmayer LJ, editors, Cultural Clinical Psychology and PTSD. Bern, Switzerland: Hogrefe Publishing. (2019). p. 3-21.

18. Kramer GP, Bernstein DA, Phares V. Introduction to Clinical Psychology. 8th ed. Cambridge: Cambridge University Press. (2019). doi: 10.1017/9781108593823

\section{AUTHOR CONTRIBUTIONS}

MT: definition, conceptualization, writing of original draft, and project administration. NR and SR: writing parts of the manuscripts, reviewing, and editing. All authors contributed to and have approved the final manuscript.

19. Masten AS, Lucke CM, Nelson KM, Stallworthy IC. Resilience in development and psychopathology: multisystem perspectives. Ann Rev Clin Psychol. (2021) 17:120307. doi: 10.1146/annurev-clinpsy-081219-120307

20. Wainwright T, Mitchell A. Psychology and the climate and environmental crisis [Special issue]. Clin Psychol Forum. (2020) 332:1-88.

21. American Psychological Association. Psychological Associations From Around the World Meet to Discuss Application of Psychology to Stem Climate Change. (2019). Available online at: https://www.apa.org/news/ press/releases/2019/11/climate-change-summit (accessed April 16, 2021).

22. Goldmann E, Galea S. Mental health consequences of disasters. Annu Rev Public Health. (2014) 35:16983. doi: 10.1146/annurev-publhealth-032013-182435

23. Pfefferbaum B, North CS. Mental health and the Covid-19 pandemic. N Engl J Med. (2020) 383:510-2. doi: 10.1056/NEJMp2008017

24. Doherty TJ. A peer reviewed journal for ecopsychology. Ecopsychology. (2009) 1:1-8. doi: 10.1089/eco.2009.0101.edi

25. Scull J. Ecopsychology: where does it fit in psychology in 2009? Trumpeter. (2008) 24:68-85.

26. American Psychological Association. Ecopsychology. (2011). Available online at: https://www.apadivisions.org/division-34/interests/ecopsychology (accessed April 18, 2021).

27. American Psychological Association. Interest Areas. (2011). Available online at: https://www.apadivisions.org/division-34/interests (accessed April 18, 2021).

28. Chalquist C. Ecotherapy: Healing With Nature in Mind. Berkeley, CA: Counterpoint Press. (2009).

29. Kahn PH, Hasbach PH. Ecopsychology: Science, Totems, and the Technological Species. Cambridge, MA: MIT Press. (2012).

30. Wilson EO. Biophilia. Cambridge, MA; London: Harvard University Press (1984).

31. Roszak TE, Gomes ME, Kanner AD. Ecopsychology: Restoring the Earth, Healing the Mind. New York, NY: Sierra Club Books. (1995).

32. Bechtel RB. Environmental psychology. Corsini Encyclopedia Psychol. (2010) 311:1-3. doi: 10.1002/9780470479216.corpsy0311

33. Bell A, Greene T, Fisher S, Baum A. Environmental Psychology. 5th ed. New York, NY: Psychology Press. (2001).

34. Clayton SD. The Oxford Handbook of Environmental and Conservation Psychology. New York, NY: Oxford University Press. (2012). doi: 10.1093/oxfordhb/9780199733026.001.0001

35. Clayton S, Myers G. Conservation Psychology: Understanding and Promoting Human Care for Nature. 2nd ed. Oxford, UK: John Wiley \& Sons. (2015).

36. Gifford R. Environmental Psychology: Principles and Practice. 4th ed. Colville, WA: Optimal Books. (2007).

37. Nasr SH. The Encounter of Man and Nature: The Spiritual Crisis of Modern Man. London: Kazi Publications (1968).

38. Swim JK, Stern PC, Doherty TJ, Clayton S, Reser JP, Weber EU, et al. Psychology's contributions to understanding and addressing global climate change. Am Psychol. (2011) 66:241-50. doi: 10.1037/a0023220

39. Pihkala P. Eco-anxiety, tragedy, and hope: psychological and spiritual dimensions of climate change. Zygon. (2018) 53:54569. doi: 10.1111/zygo.12407

40. Usher K, Durkin J, Bhullar N. Eco-anxiety: how thinking about climate change-related environmental decline is affecting our mental health. Int J Ment Health Nurs. (2019) 28:1233-4. doi: 10.1111/inm.12673

41. Ojala M. Eco-anxiety. RSA J. (2018) 164:10-5.

42. Cooley SJ, Jones CR, Kurtz A, Robertson N. "Into the Wild": a metasynthesis of talking therapy in natural outdoor spaces. Clin Psychol Rev. (2020) 77:101841. doi: 10.1016/j.cpr.2020.101841 
43. Park BJ, Tsunetsugu Y, Kasetani T, Hirano H, Kagawa T, Sato M, et al. Physiological effects of Shinrin-yoku (taking in the atmosphere of the forest) - using salivary cortisol and cerebral activity as indicators. J Physiol Anthropol. (2007) 26:123-8. doi: 10.2114/jpa2.26.123

44. Bratman GN, Hamilton JP, Daily GC. The impacts of nature experience on human cognitive function and mental health. Ann N Y Acad Sci. (2012) 1249:118-36. doi: 10.1111/j.1749-6632.2011.06400.x

45. Kaplan R, Kaplan S. The Experience of Nature: A Psychological Perspective. Cambridge, New York: Cambridge University Press. (1989).

46. Ulrich RS. Aesthetic and affective response to natural environment. In Altman I, Wohlwill JF, editors. Behavior and the Natural Environment. Boston, MA: Springer. (1983). p. 85-125. doi: 10.1007/978-1-4613-3539-9_4

47. Ulrich RS, Simons RF, Losito BD, Fiorito E, Miles MA, Zelson M. Stress recovery during exposure to natural and urban environments. J Environ Psychol. (1991) 11:201-30. doi: 10.1016/S0272-4944(05)80184-7

48. Intergovernmental Panel on Climate Change. Global Warming of $1.5^{\circ} \mathrm{C}: \mathrm{An}$ IPCC Special Report on the Impacts of Global Warming of $1.5^{\circ} \mathrm{C}$ Above PreIndustrial Levels and Related Global Greenhouse Gas Emission Pathways, in the Context of Strenthening the Global Response to the Threat of Climate Change, Sustainable Devleopment, and Efforts to Erdicate Poverty - Summary for Policy Makers. World Meteorological Organization. (2018). Available online at: https://www.ipcc.ch/sr15/ (accessed September 24, 2020).

49. Philip S, Martin RV, van Donkelaar A, Lo JW, Wang Y, Chen D, et al. Global chemical composition of ambient fine particulate matter for exposure assessment. Environ Sci Technol. (2014) 48:13060-8. doi: 10.1021/es502965b

50. World Health Organization. Air Pollution. (2020). Available online at: https://www.who.int/health-topics/air-pollution (accessed September 24, 2020).

51. Jambeck JR, Geyer R, Wilcox C, Siegler TR, Perryman M, Andrady A, et al. Marine pollution. Plastic waste inputs from land into the ocean. Science. (2015) 347:768-71. doi: 10.1126/science.1260352

52. Sammarco PW, Kolian SR, Warby RA, Bouldin JL, Subra WA, Porter SA. Distribution and concentrations of petroleum hydrocarbons associated with the BP/Deepwater Horizon Oil Spill, Gulf of Mexico. Mar Pollut Bull. (2013) 73:129-43. doi: 10.1016/j.marpolbul.2013.05.029

53. Intergovernmental Science-Policy Platform on Biodiversity and Ecosystem Services. Media Release: Nature's Dangerous Decline "Unprecedented"; Species Extinction Rates “Accelerating”. (2019). Available online at: https://ipbes.net/ news/Media-Release-Global-Assessment (accessed February 11, 2021).

54. Barnosky AD, Matzke N, Tomiya S, Wogan GO, Swartz B, Quental TB, et al. Has the Earth's sixth mass extinction already arrived? Nature. (2011) 471:51-7. doi: 10.1038/nature09678

55. Cardoso P, Barton PS, Birkhofer K, Chichorro F, Deacon C, Fartmann T, et al. Scientists' warning to humanity on insect extinctions. Biol Conserv. (2020) 242:108426. doi: 10.1016/j.biocon.2020.108426

56. Mammola S, Cardoso P, Culver DC, Deharveng L, Ferreira RL, Fišer C, et al. Scientists' warning on the conservation of subterranean ecosystems. Bioscience. (2019) 69:641-50. doi: 10.1093/biosci/biz064

57. Albert JS, Destouni G, Duke-Sylvester SM, Magurran AE, Oberdorff T, Reis $\mathrm{RE}$, et al. Scientists' warning to humanity on the freshwater biodiversity crisis. Ambio. (2020) 8:1-10. doi: 10.1007/s13280-020-01318-8

58. Doherty TJ, Clayton S. The psychological impacts of global climate change. Am Psychol. (2011) 66:265-76. doi: 10.1037/a0023141

59. Clemens V, von Hirschhausen E, Fegert JM. Report of the intergovernmental panel on climate change: implications for the mental health policy of children and adolescents in Europe-a scoping review. Eur Child Adolesc Psychiatry. (2020) 1-13. doi: 10.1007/s00787-020-01615-3

60. Haines A, Kovats RS, Campbell-Lendrum D, Corvalán C. Climate change and human health: impacts, vulnerability and public health. Public Health. (2006) 120:585-96. doi: 10.1016/j.puhe.2006.01.002

61. Dodd W, Scott P, Howard C, Scott C, Rose C, Cunsolo A, et al. Lived experience of a record wildfire season in the Northwest Territories, Canada. Can J Public Health. (2018) 109:327-37. doi: 10.17269/s41997-018-0070-5

62. McLaughlin KA, Berglund P, Gruber MJ, Kessler RC, Sampson NA, Zaslavsky AM. Recovery from PTSD following Hurricane Katrina. Depress Anxiety. (2011) 28:439-46. doi: 10.1002/da.20790

63. Paxson C, Fussell E, Rhodes J, Waters M. Five years later: recovery from post traumatic stress and psychological distress among low-income mothers affected by Hurricane Katrina. Soc Sci Med. (2012) 74:1507. doi: 10.1016/j.socscimed.2011.10.004

64. Raker EJ, Lowe SR, Arcaya MC, Johnson ST, Rhodes J, Waters MC. Twelve years later: the long-term mental health consequences of Hurricane Katrina. Soc Sci Med. (2019) 242:112610. doi: 10.1016/j.socscimed.2019. 112610

65. Rataj E, Kunzweiler K, and Garthus-Niegel, S. Extreme weather events in developing countries and related injuries and mental health disorders - a systematic review. BMC Public Health. (2016) 16:1020. doi: 10.1186/s12889-016-3692-7

66. Rhodes J, Chan C, Paxson C, Rouse CE, Waters M, Fussell E. The impact of hurricane Katrina on the mental and physical health of lowincome parents in New Orleans. Am J Orthopsychiatry. (2010) 80:23747. doi: 10.1111/j.1939-0025.2010.01027.x

67. Fernandez A, Black J, Jones M, Wilson L, Salvador-Carulla L, Astell-Burt T, et al. Flooding and mental health: a systematic mapping review. PLoS ONE. (2015) 10:e0119929. doi: 10.1371/journal.pone.0119929

68. Trombley J, Chalupka S, Anderko L. Climate change and mental health. Am J Nurs. (2017) 117:44-52. doi: 10.1097/01.NAJ.0000515232.51795.fa

69. Schoenbaum M, Butler B, Kataoka S, Norquist G, Springgate B, Sullivan $\mathrm{G}$, et al. Promoting mental health recovery after hurricanes Katrina and Rita: what can be done at what cost. Arch Gen Psychiatry. (2009) 66:90614. doi: 10.1001/archgenpsychiatry.2009.77

70. Galea S, Nandi A, Vlahov D. The epidemiology of posttraumatic stress disorder after disasters. Epidemiol Rev. (2005) 27:78-91. doi: 10.1093/epirev/mxi003

71. Dumont C, Haase E, Dolber T, Lewis J, Coverdale J. Climate change and risk of completed suicide. J Nerv Ment Dis. (2020) 208:55965. doi: 10.1097/NMD.0000000000001162

72. Rifkin DI, Long MW, Perry MJ. Climate change and sleep: a systematic review of the literature and conceptual framework. Sleep Med Rev. (2018) 42:3-9. doi: 10.1016/j.smrv.2018.07.007

73. Shiloh R, Shapira A, Potchter O, Hermesh H, Popper M, Weizman A. Effects of climate on admission rates of schizophrenia patients to psychiatric hospitals. Eur Psychiatry. (2005) 20:61-4. doi: 10.1016/j.eurpsy.2004.09.020

74. Burke M, González F, Baylis P, Heft-Neal S, Baysan C, Basu S, et al. Higher temperatures increase suicide rates in the United States and Mexico. Nat Clim Chang. (2018) 8:723-9. doi: 10.1038/s41558-018-0222-x

75. Obradovich N, Migliorini R, Paulus MP, Rahwan I. Empirical evidence of mental health risks posed by climate change. Proc Natl Acad Sci USA. (2018) 115:10953-8. doi: 10.1073/pnas.1801528115

76. O’Brien LV, Berry HL, Coleman C, Hanigan IC. Drought as a mental health exposure. Environ Res. (2014) 131:181-7. doi: 10.1016/j.envres.2014.03.014

77. Edwards B, Gray M, Hunter B. The impact of drought on mental health in rural and regional Australia. Soc Indicat Res. (2015) 121:17794. doi: 10.1007/s11205-014-0638-2

78. Misra AK. Climate change and challenges of water and food security. Int $J$ Sustain Built Environ. (2014) 3:153-65. doi: 10.1016/j.ijsbe.2014.04.006

79. Kovats S, Akhtar R. Climate, climate change and human health in Asian cities. Environ Urbanization. (2008) 20:16575. doi: $10.1177 / 0956247808089154$

80. Mekonnen MM, Hoekstra AY. Four billion people facing severe water scarcity. Sci Adv. (2016) 2:e1500323. doi: 10.1126/sciadv.1500323

81. Jones AD. Food insecurity and mental health status: a global analysis of 149 countries. Am J Prev Med. (2017) 53:26473. doi: 10.1016/j.amepre.2017.04.008

82. Adams EA, Stoler J, Adams Y. Water insecurity and urban poverty in the Global South: implications for health and human biology. Am J Hum Biol. (2020) 32:e23368. doi: 10.1002/ajhb.23368

83. Wutich A, Brewis A, Tsai A. Water and mental health. Wiley Interdiscipl Rev Water. (2020) 7:e1461. doi: 10.1002/wat2.1461

84. Pourmotabbed A, Moradi S, Babaei A, Ghavami A, Mohammadi H, Jalili C, et al. Food insecurity and mental health: a systematic review and meta-analysis - CORRIGENDUM. Public Health Nutr. (2020) 23:1854. doi: 10.1017/S136898001900435X

85. Buoli M, Grassi S, Caldiroli A, Carnevali GS, Mucci F, Iodice S, et al. Is there a link between air pollution and mental disorders? Environ Int. (2018) 118:154-68. doi: 10.1016/j.envint.2018.05.044 
86. Wang R, Liu Y, Xue D, Yao Y, Liu P, Helbich M. Cross-sectional associations between long-term exposure to particulate matter and depression in China: the mediating effects of sunlight, physical activity, and neighborly reciprocity. J Affect Disord. (2019) 249:8-14. doi: 10.1016/j.jad.2019.02.007

87. Roberts S, Arseneault L, Barratt B, Beevers S, Danese A, Odgers $\mathrm{CL}$, et al. Exploration of $\mathrm{NO}_{2}$ and $\mathrm{PM}_{2.5}$ air pollution and mental health problems using high-resolution data in London-based children from a UK longitudinal cohort study. Psychiatry Res. (2019) 272:817. doi: 10.1016/j.psychres.2018.12.050

88. Gu X, Liu Q, Deng F, Wang X, Lin H, Guo X, et al. Association between particulate matter air pollution and risk of depression and suicide: systematic review and meta-analysis. Br J Psychiatry. (2019) 215:45667. doi: 10.1192/bjp.2018.295

89. Block ML, Calderon-Garciduenas L. Air pollution: mechanisms of neuroinflammation and CNS disease. Trends Neurosci. (2009) 32:50616. doi: 10.1016/j.tins.2009.05.009

90. Oudin A. Short review: air pollution, noise and lack of greenness as risk factors for Alzheimer's disease - epidemiologic and experimental evidence. Neurochem Int. (2020) 134:104646. doi: 10.1016/j.neuint.2019.104646

91. Chen H, Kwong JC, Copes R, Tu K, Villeneuve PJ, van Donkelaar A, et al. Living near major roads and the incidence of dementia, Parkinson's disease, and multiple sclerosis: a population-based cohort study. Lancet. (2017) 389:718-26. doi: 10.1016/S0140-6736(16)32399-6

92. Albrecht G, Sartore GM, Connor L, Higginbotham N, Freeman S, Kelly B, et al. Solastalgia: the distress caused by environmental change. Australas Psychiatry. (2007) 15:S95-8. doi: 10.1080/10398560701701288

93. Ellis NR, Albrecht GA. Climate change threats to family farmers' sense of place and mental wellbeing: a case study from the Western Australian Wheatbelt. Soc Sci Med. (2017) 175:161-8. doi: 10.1016/j.socscimed.2017.01.009

94. Albrecht G. Chronic environmental change: emerging "psychoterratic" syndromes. In: Weissbecker I, editor, Climate Change and Human Well-Being. New York, NY: Springer. (2011). p. 43-56. doi: 10.1007/978-1-4419-9742-5_3

95. Poushter J, Huang C. Climate change still seen as the top global threat, but cyberattacks a rising concern. Pew Research Center. (2019) 10:1-37.

96. Strife SJ. Children's environmental concerns: expressing ecophobia. J Environ Educ. (2012) 43:37-54. doi: 10.1080/00958964.2011.602131

97. American Psychological Association. Majority of US adults believe climate change is most important issue today: nearly half of 18-34 year olds say that stress about climate change affects their lives. ScienceDaily. (2020). Available online at: https://www.sciencedaily.com/releases/2020/02/ 200207095418.htm (accessed August 4, 2020).

98. Clayton S. Climate anxiety: psychological responses to climate change. $J$ Anxiety Disord. (2020) 74:102263. doi: 10.1016/j.janxdis.2020.102263

99. Clayton S, Karazsia BT. Development and validation of a measure of climate change anxiety. J Environ Psychol. (2020) 69:101434. doi: 10.1016/j.jenvp.2020.101434

100. Morton T. Hyperobjects: Philosophy and Ecology After the End of the World. Minneapolis, MN: University of Minnesota Press. (2013).

101. Maercker A, Lorenz L. Adjustment disorder diagnosis: improving clinical utility. World J Biol Psychiatry. (2018) 19:S3-13. doi: 10.1080/15622975.2018.1449967

102. Lederbogen F, Kirsch P, Haddad L, Streit F, Tost H, Schuch P, et al. City living and urban upbringing affect neural social stress processing in humans. Nature. (2011) 474:498-501. doi: 10.1038/nature10190

103. Sundquist K, Frank G, Sundquist J. Urbanisation and incidence of psychosis and depression: follow-up study of 4.4 million women and men in Sweden. Br J Psychiatry. (2004) 184:293-8. doi: 10.1192/bjp.184.4.293

104. Amudhan S, Gururaj G, Varghese M, Benegal V, Rao GN, Sheehan $\mathrm{DV}$, et al. A population-based analysis of suicidality and its correlates: findings from the National Mental Health Survey of India:201516. Lancet Psychiatry. (2020) 7:41-51. doi: 10.1016/S2215-0366(19) 30404-3

105. Chang HT, Wu CD, Pan WC, Lung SC, Su HJ. Association between surrounding greenness and schizophrenia: a Taiwanese cohort study. Int J Environ Res Public Health. (2019) 16:1415. doi: 10.3390/ijerph16081415
106. Ohrnberger J, Fichera E, Sutton M. The relationship between physical and mental health: a mediation analysis. Soc Sci Med. (2017) 195:429. doi: 10.1016/j.socscimed.2017.11.008

107. Ameratunga S, Woodward A. Rising injuries in a hotter climate. Nat Med. (2020) 26:22-3. doi: 10.1038/s41591-019-0728-4

108. Parks RM, Bennett JE, Tamura-Wicks H, Kontis V, Toumi R, Danaei G, et al. Anomalously warm temperatures are associated with increased injury deaths. Nat Med. (2020) 26:65-70. doi: 10.1038/s41591-019-0721-y

109. Tawatsupa B, Yiengprugsawan V, Kjellstrom T, Berecki-Gisolf J, Seubsman SA, Sleigh A. Association between heat stress and occupational injury among Thai workers: findings of the Thai Cohort Study. Ind Health. (2013) 51:3446. doi: 10.2486/indhealth.2012-0138

110. Kim KH, Kabir E, Ara Jahan S. A review of the consequences of global climate change on human health. J Environ Sci Health C Environ Carcinog Ecotoxicol Rev. (2014) 32:299-318. doi: 10.1080/10590501.2014.941279

111. Kjellstrom T, Butler AJ, Lucas RM, Bonita R. Public health impact of global heating due to climate change: potential effects on chronic non-communicable diseases. Int J Public Health. (2010) 55:97-103. doi: 10.1007/s00038-009-0090-2

112. Norloei S, Jafari MJ, Omidi L, Khodakarim S, Bashash D, Abdollahi MB, et al. The effects of heat stress on a number of hematological parameters and levels of thyroid hormones in foundry workers. Int J Occup Saf Ergon. (2017) 23:481-90. doi: 10.1080/10803548.2016.1246122

113. Pranskunas A, Pranskuniene Z, Milieskaite E, Daniuseviciute L, Kudreviciene A, Vitkauskiene A, et al. Effects of whole body heat stress on sublingual microcirculation in healthy humans. Eur J Appl Physiol. (2015) 115:157-65. doi: 10.1007/s00421-014-2999-2

114. Piil JF, Lundbye-Jensen J, Christiansen L, Ioannou L, Tsoutsoubi L, Dallas $\mathrm{CN}$, et al. High prevalence of hypohydration in occupations with heat stressPerspectives for performance in combined cognitive and motor tasks. PLoS ONE. (2018) 13:e0205321. doi: 10.1371/journal.pone.0205321

115. Kovats RS, Hajat S. Heat stress and public health: a critical review. Annu Rev Public Health. (2008) 29:4155. doi: 10.1146/annurev.publhealth.29.020907.090843

116. Kenny GP, Yardley J, Brown C, Sigal RJ, Jay O. Heat stress in older individuals and patients with common chronic diseases. CMAJ. (2010) 182:1053-60. doi: 10.1503/cmaj.081050

117. Kwok JS, Chan TY. Recurrent heat-related illnesses during antipsychotic treatment. Ann Pharmacother. (2005) 39:1940-2. doi: 10.1345/aph.1G130

118. Stollberger C, Lutz W, Finsterer J. Heat-related side-effects of neurological and non-neurological medication may increase heatwave fatalities. Eur J Neurol. (2009) 16:879-82. doi: 10.1111/j.1468-1331.2009.02581.x

119. Calderon-Garciduenas L, Calderon-Garciduenas A, Torres-Jardon R, AvilaRamirez J, Kulesza RJ, Angiulli AD. Air pollution and your brain: what do you need to know right now. Prim Health Care Res Dev. (2015) 16:32945. doi: 10.1017/S146342361400036X

120. Cann KF, Thomas DR, Salmon RL, Wyn-Jones AP, Kay D. Extreme waterrelated weather events and waterborne disease. Epidemiol Infection. (2013) 141:671-86. doi: 10.1017/S0950268812001653

121. Davies GI, McIver L, Kim Y, Hashizume M, Iddings S, Chan V. Waterborne diseases and extreme weather events in Cambodia: review of impacts and implications of climate change. Int J Environ Res Public Health. (2015) 12:191-213. doi: 10.3390/ijerph120100191

122. Caminade C, McIntyre KM, Jones AE. Impact of recent and future climate change on vector-borne diseases. Ann N Y Acad Sci. (2019) 1436:15773. doi: 10.1111/nyas.13950

123. Semenza JC, Suk JE. Vector-borne diseases and climate change: a European perspective. FEMS Microbiol Lett. (2018) 365:fnx244. doi: 10.1093/femsle/fnx244

124. Mills JN, Gage KL, Khan AS. Potential influence of climate change on vectorborne and zoonotic diseases: a review and proposed research plan. Environ Health Perspect. (2010) 118:1507-14. doi: 10.1289/ehp.0901389

125. Dantzer R, O’Connor JC, Freund GG, Johnson RW, Kelley KW. From inflammation to sickness and depression: when the immune system subjugates the brain. Nat Rev Neurosci. (2008) 9:46-56. doi: 10.1038/nrn2297

126. Couzin-Frankel, J. Inflammation bares a dark side. Science. (2010) 330:1621. doi: 10.1126/science.330.6011.1621 
127. Danesh J, Kaptoge S, Mann AG, Sarwar N, Wood A, Angleman SB, et al. Long-term interleukin-6 levels and subsequent risk of coronary heart disease: two new prospective studies and a systematic review. PLoS Med. (2008) 5:e78. doi: 10.1371/journal.pmed.0050078

128. Hunter CA, Jones SA. IL- 6 as a keystone cytokine in health and disease. Nat Immunol. (2015) 16:448-57. doi: 10.1038/ni.3153

129. Yaffe K, Kanaya A, Lindquist K, Simonsick EM, Harris T, Shorr RI, et al. The metabolic syndrome, inflammation, and risk of cognitive decline. JAMA. (2004) 292:2237-42. doi: 10.1001/jama.292.18.2237

130. Wolfe SE, Tubi A. Terror management theory and mortality awareness: a missing link in climate response studies? Wiley Interdiscipl Rev Climate Change. (2019) 10:566. doi: 10.1002/wcc.566

131. Berry HL, Waite TD, Dear KBG, Capon AG, Murray V. The case for systems thinking about climate change and mental health. Nat Clim Chang. (2018) 8:282-90. doi: 10.1038/s41558-018-0102-4

132. Levy BS, Patz JA. Climate change, human rights, and social justice. Ann Glob Health. (2015) 81:310-22. doi: 10.1016/j.aogh.2015.08.008

133. Bizer GY. Who's bothered by an unfair world? The emotional response to unfairness scale. Personal Individ Differ. (2020) 159:109882. doi: 10.1016/j.paid.2020.109882

134. Kellert SR, Wilson EO. The Biophilia Hypothesis. Washington, DC: Island Press. (1993).

135. Cunsolo Willox AC, Harper SL, Edge VL, Landman K, Houle K, Ford JD, et al. The land enriches the soul: on climatic and environmental change, affect, and emotional health and well-being in Rigolet, Nunatsiavut, Canada. Emot Space Soc. (2013) 6:14-24. doi: 10.1016/j.emospa.2011.08.005

136. Wulsin L, Herman J, Thayer JF. Stress, autonomic imbalance, and the prediction of metabolic risk: a model and a proposal for research. Neurosci Biobehav Rev. (2018) 86:12-20. doi: 10.1016/j.neubiorev.2017.12.010

137. Fries E, Hesse J, Hellhammer J, Hellhammer DH. A new view on hypocortisolism. Psychoneuroendocrinology. (2005) 30:1010-6. doi: 10.1016/j.psyneuen.2005.04.006

138. Miller GE, Chen E, Zhou ES. If it goes up, must it come down? Chronic stress and the hypothalamic-pituitary-adrenocortical axis in humans. Psychol Bull. (2007) 133:25-45. doi: 10.1037/0033-2909.133.1.25

139. Rohleder N. Stimulation of systemic low-grade inflammation by psychosocial stress. Psychosomatic medicine. (2014) 76:1819. doi: 10.1097/PSY.0000000000000049

140. Hänsel A, Hong S, Cámara RJ, Von Kaenel, R. Inflammation as a psychophysiological biomarker in chronic psychosocial stress. Neurosci Biobehav Rev. (2010) 35:115-21. doi: 10.1016/j.neubiorev.2009.12.012

141. Slavich GM, Irwin MR. From stress to inflammation and major depressive disorder: a social signal transduction theory of depression. Psychol Bull. (2014) 140:774-815. doi: 10.1037/a0035302

142. Alvarez HA. O., Kubzansky LD, Carnpen MJ, Slavich GM. Early life stress, air pollution, inflammation, and disease: an integrative review and immunologic model of social-environmental adversity and lifespan health. Neurosci Biobehav Rev. (2018) 92:226-42. doi: 10.1016/j.neubiorev.2018.06.002

143. Kumar MB, Tjepkema M. Suicide Among First Nations people, Métis and Inuit (2011-2016): Findings From the 2011 Canadian Census Health and Environment Cohort (CanCHEC). (2019) Available online at: https://www150.statcan.gc.ca/n1/en/catalogue/99-011-X2019001 (accessed September 24, 2020).

144. Giddens A. The Politics of Climate Change. Cambridge and Malden, MA: Polity. (2009).

145. Dunlap RE. Climate change skepticism and denial: an introduction. Am Behav Scientist. (2013) 57:691-8. doi: 10.1177/00027642134 77097

146. McCright AM, Dunlap RE. Cool dudes: the denial of climate change among conservative white males in the United States. Glob Environ Change. (2011) 21:1163-72. doi: 10.1016/j.gloenvcha.2011.06.003

147. Stoll-Kleemann S, O'Riordan T, Jaeger CC. The psychology of denial concerning climate mitigation measures: evidence from Swiss focus groups. Glob Environ Change. (2001) 11:10717. doi: 10.1016/S0959-3780(00)00061-3

148. Wong-Parodi G, Feygina I. Understanding and countering the motivated roots of climate change denial. Curr Opin Environ Sustain. (2020) 42:604. doi: 10.1016/j.cosust.2019.11.008
149. Becker E. The Denial of Death. New York, NY: Free Press. (1973).

150. Segerstrom SC, Miller GE. Psychological stress and the human immune system: a meta-analytic study of 30 years of inquiry. Psychol Bullet. (2004) 130:601-30. doi: 10.1037/0033-2909.130.4.601

151. Vanaken GJ, Danckaerts M. Impact of green space exposure on children's and adolescents' mental health: a systematic review. Int J Environ Res Public Health. (2018) 15:2668. doi: 10.3390/ijerph15122668

152. Bell JF, Wilson JS, Liu GC. Neighborhood greenness and 2-year changes in body mass index of children and youth. Am J Prev Med. (2008) 35:54753. doi: 10.1016/j.amepre.2008.07.006

153. Fong KC, Hart JE, James P. A review of epidemiologic studies on greenness and health: updated literature through 2017. Curr Environ Health Rep. (2018) 5:77-87. doi: 10.1007/s40572-018-0179-y

154. Markevych I, Schoierer J, Hartig T, Chudnovsky A, Hystad P, Dzhambov AM, et al. Exploring pathways linking greenspace to health: theoretical and methodological guidance. Environ Res. (2017) 158:301-17. doi: 10.1016/j.envres.2017.06.028

155. Dexter PR, Miller DK, Clark DO, Weiner M, Harris LE, Livin L, et al. Preparing for an aging population and improving chronic disease management. AMIA Annu Symp Proc. (2010) 2010:162-6.

156. Thompson Coon J, Boddy K, Stein K, Whear R, Barton J, Depledge MH. Does participating in physical activity in outdoor natural environments have a greater effect on physical and mental well-being than physical activity indoors? A systematic review. Environ Sci Technol. (2011) 45:176172. doi: 10.1021/es102947t

157. James P, Banay RF, Hart JE, Laden F. A review of the health benefits of greenness. Curr Epidemiol Rep. (2015) 2:131-42. doi: 10.1007/s40471-015-0043-7

158. Rios R, Aiken LS, Zautra AJ. Neighborhood contexts and the mediating role of neighborhood social cohesion on health and psychological distress among Hispanic and non-Hispanic residents. Ann Behav Med. (2012) 43:5061. doi: 10.1007/s12160-011-9306-9

159. Lan L, Tsuzuki K, Liu YF, Lian ZW. Thermal environment and sleep quality: a review. Energy Buildings. (2017) 149:10113. doi: 10.1016/j.enbuild.2017.05.043

160. Freeman D, Sheaves B, Goodwin GM, Yu LM, Nickless A, Harrison PJ, et al. The effects of improving sleep on mental health (OASIS): a randomised controlled trial with mediation analysis. Lancet Psychiatry. (2017) 4:74958. doi: 10.1016/S2215-0366(17)30328-0

161. Goin DE, Rudolph KE, Ahern J. Impact of drought on crime in California: a synthetic control approach. PLoS ONE. (2017) 12:e0185629. doi: 10.1371/journal.pone.0185629

162. Epstein A, Bendavid E, Nash D, Charlebois ED, Weiser SD. Drought and intimate partner violence towards women in 19 countries in sub-Saharan Africa during 2011-2018: a population-based study. PLoS Med. (2020) 17:e1003064. doi: 10.1371/journal.pmed.1003064

163. Allen J, Balfour R, Bell R, Marmot M. Social determinants of mental health. Int Rev Psychiatry. (2014) 26:392-407. doi: 10.3109/09540261.2014.928270

164. Taylor SE. Social support: a review. In: Friedman HS, editor, Oxford Library of Psychology. The Oxford Handbook of Health Psychology. New York, NY: Oxford University Press. (2011). p. 189-214.

165. Lundgren K, Kuklane K, Gao C, Holmer I. Effects of heat stress on working populations when facing climate change. Ind Health. (2013) 51:315. doi: 10.2486/indhealth.2012-0089

166. Vins H, Bell J, Saha S, Hess JJ. The mental health outcomes of drought: a systematic review and causal process diagram. Int J Environ Res Public Health. (2015) 12:13251-75. doi: 10.3390/ijerph121013251

167. Gifford E, Gifford R. The largely unacknowledged impact of climate change on mental health. Bullet Atomic Scientists. (2016) 72:2927. doi: 10.1080/00963402.2016.1216505

168. Joy KJ, Paranjape S. Understanding water conflicts in South Asia. Contemporary Perspectiv. (2007) 1:29-57. doi: 10.1177/223080750700100202

169. Lowe SR, Rhodes JE. Trajectories of psychological distress among lowincome, female survivors of Hurricane Katrina. Am J Orthopsychiatry. (2013) 83:398-412. doi: 10.1111/ajop.12019

170. Galea S, Brewin CR, Gruber M, Jones RT, King DW, King LA, et al. Exposure to hurricane-related stressors and mental illness after Hurricane Katrina. Arch Gen Psychiatry. (2007) 64:1427-34. doi: 10.1001/archpsyc.64.12.1427 
171. Lowe SR, Sampson L, Gruebner O, Galea S. Psychological resilience after Hurricane Sandy: the influence of individual-and community-level factors on mental health after a large-scale natural disaster. PLOS ONE. (2015) 10:e0125761. doi: 10.1371/journal.pone.0125761

172. Hall NL, Crosby L. Climate change impacts on health in remote indigenous communities in Australia. Int J Environ Health Res. (2020) 2020:116. doi: 10.1080/09603123.2020.1777948

173. Luber G, McGeehin M. Climate change and extreme heat events. Am J Prev Med. (2008) 35:429-35. doi: 10.1016/j.amepre.2008.08.021

174. Okkels N, Kristiansen CB, Munk-Jorgensen P, Sartorius N. Urban mental health: challenges and perspectives. Curr Opin Psychiatry. (2018) 31:25864. doi: 10.1097/YCO.0000000000000413

175. Zhang Y, Bi P, Hiller JE. Climate change and disability-adjusted life years. $J$ Environ Health. (2007) 70:32-6.

176. Gehring U, Wijga AH, Hoek G, Bellander T, Berdel D, Bruske I, et al. Exposure to air pollution and development of asthma and rhinoconjunctivitis throughout childhood and adolescence: a population-based birth cohort study. Lancet Respir Med. (2015) 3:933-42. doi: 10.1016/S2213-2600(15)00426-9

177. Burke SEL, Sanson AV, Van Hoorn J. The psychological effects of climate change on Children. Curr Psychiatry Rep. (2018) 20:35. doi: 10.1007/s11920-018-0896-9

178. United Nations International Children's Emergency Fund. Childhood Under Treat. The State of the World's Children 2005. (2020). Available online at: https://www.unicef.org/sowc05/english/poverty.html (accessed October 16, 2020).

179. Lupien SJ, McEwen BS, Gunnar MR, Heim C. Effects of stress throughout the lifespan on the brain, behaviour and cognition. Nat Rev Neurosci. (2009) 10:434-45. doi: 10.1038/nrn2639

180. Gamble JL, Hurley BJ, Schultz PA, Jaglom WS, Krishnan N, Harris M. Climate change and older Americans: state of the science. Environ Health Perspect. (2013) 121:15-22. doi: 10.1289/ehp.1205223

181. Jonkman SN, Maaskant B, Boyd E, Levitan ML. Loss of life caused by the flooding of New Orleans after Hurricane Katrina: analysis of the relationship between flood characteristics and mortality. Risk Anal. (2009) 29:67698. doi: 10.1111/j.1539-6924.2008.01190.x

182. Kim Y, Kim H, Kim DS. Association between daily environmental temperature and suicide mortality in Korea (2001-2005). Psychiatry Res. (2011) 186:390-6. doi: 10.1016/j.psychres.2010.08.006

183. Onwutuebe CI. Patriarchy and women vulnerability to adverse climate change in Nigeria. Sage Open. (2019) 9:2158244019825914. doi: 10.1177/2158244019825914

184. Martin-Latry K, Goumy MP, Latry P, Gabinski C, Begaud B, Faure I, et al. Psychotropic drugs use and risk of heat-related hospitalisation. Eur Psychiatry. (2007) 22:335-8. doi: 10.1016/j.eurpsy.2007. 03.007

185. Rutter, M. Resilience as a dynamic concept. Dev Psychopathol. (2012) 24:33544. doi: 10.1017/S0954579412000028

186. Norris FH, Tracy M, Galea S. Looking for resilience: understanding the longitudinal trajectories of responses to stress. Soc Sci Med. (2009) 68:2190-8. doi: 10.1016/j.socscimed.2009. 03.043

187. Liu JJ, Reed M, Girard TA. Advancing resilience: an integrative, multi-system model of resilience. Personal Individ Differ. (2017) 111:111-8. doi: 10.1016/j.paid.2017. 02.007
188. Benight CC, Swift E, Sanger J, Smith A, Zeppelin D. Coping self-efficacy as a mediator of distress following a natural disaster. J Appl Soc Psychol. (1999) 29:2443-64. doi: 10.1111/j.1559-1816.1999.tb00120.x

189. Adeola FO. Katrina cataclysm: does duration of residency and prior experience affect impacts, evacuation, and adaptation behavior among survivors? Environ Behav. (2009) 41:45989. doi: 10.1177/0013916508316651

190. Clayton S. Mental health risk and resilience among climate scientists. Nat Climate Change. (2018) 8:260-1. doi: 10.1038/s41558-018-0123-z

191. de Keijzer C, Tonne C, Basagana X, Valentin A, Singh-Manoux A, Alonso $J$, et al. Residential surrounding greenness and cognitive decline: a 10year follow-up of the Whitehall II cohort. Environ Health Perspect. (2018) 126:077003. doi: 10.1289/EHP2875

192. Gascon M, Zijlema W, Vert C, White MP, Nieuwenhuijsen MJ. Outdoor blue spaces, human health and well-being: a systematic review of quantitative studies. Int J Hyg Environ Health. (2017) 220:1207-21. doi: 10.1016/j.ijheh.2017.08.004

193. Velarde MD, Fry G, Tveit M. Health effects of viewing landscapes Landscape types in environmental psychology. Urban Forestry Urban Greening. (2007) 6:199-212. doi: 10.1016/j.ufug.2007.07.001

194. Thoma MV, La Marca R, Bronnimann R, Finkel L, Ehlert U, Nater UM. The effect of music on the human stress response. PLoS ONE. (2013) 8:e70156. doi: 10.1371/journal.pone.0070156

195. Maas J, Verheij RA, de Vries S, Spreeuwenberg P, Schellevis FG, Groenewegen PP. Morbidity is related to a green living environment. J Epidemiol Community Health. (2009) 63:96773. doi: 10.1136/jech.2008.079038

196. Callaghan A, McCombe G, Harrold A, McMeel C, Mills G, MooreCherry $\mathrm{N}$, et al. The impact of green spaces on mental health in urban settings: a scoping review. J Ment Health. (2020) 2020:115. doi: 10.1080/09638237.2020.1755027

197. Tedeschi RG, Calhoun LG. Posttraumatic growth: conceptual foundations and empirical evidence. Psychol Inquiry. (2004) 15:1-18. doi: 10.1207/s15327965pli1501_01

198. Kessler RC, Galea S, Jones RT, Parker HA, Hurricane Katrina Community Advisory Group. Mental illness and suicidality after Hurricane Katrina. Bull World Health Organ. (2006) 84:930-9. doi: 10.2471/BLT.06.033019

199. Norris FH, Friedman MJ, Watson PJ, Byrne CM, Diaz E, Kaniasty K. 60,000 disaster victims speak: Part I. An empirical review of the empirical literature:1981-2001. Psychiatry. (2002) 65:207-39. doi: 10.1521/psyc.65.3.207.20173

200. Sickel AE, Seacat JD, Nabors NA. Mental health stigma: impact on mental health treatment attitudes and physical health. J Health Psychol. (2019) 24:586-99. doi: 10.1177/1359105316681430

Conflict of Interest: The authors declare that the research was conducted in the absence of any commercial or financial relationships that could be construed as a potential conflict of interest.

Copyright (C) 2021 Thoma, Rohleder and Rohner. This is an open-access article distributed under the terms of the Creative Commons Attribution License (CC BY). The use, distribution or reproduction in other forums is permitted, provided the original author(s) and the copyright owner(s) are credited and that the original publication in this journal is cited, in accordance with accepted academic practice. No use, distribution or reproduction is permitted which does not comply with these terms. 